\title{
Leader mistreatment, employee hostility, and deviant behaviors: Integrating self- uncertainty and thwarted needs perspectives on deviance
}

\author{
David M. Mayer ${ }^{1}$ \\ Corresponding Author \\ University of Michigan \\ Stefan Thau ${ }^{1}$ \\ Corresponding Author \\ London Business School \\ Kristina M. Workman \\ University of Michigan \\ Marius Van Dijke \\ Erasmus University \\ David De Cremer \\ Erasmus University
}

\begin{abstract}
Integrating self-uncertainty management and thwarted needs perspectives on leader mistreatment and workplace deviance, we examine when and why leader mistreatment is associated with workplace deviance. We propose that competence uncertainty strengthens the relationship between leader mistreatment and workplace deviance and that hostility mediates this interactive effect. Four field studies and one experiment support the hypotheses. The first two studies provide evidence for the predicted interaction between leader mistreatment and competence uncertainty, and the next three studies demonstrate that hostility mediates this interactive effect. We discuss an extended social exchange explanation of workplace deviance and highlight the psychological interplay between motives, cognition, and affect in reciprocating leader mistreatment.
\end{abstract}

KEYWORDS: Leadership, Deviance, Self, Uncertainty, Competence

\section{Introduction}

Some authorities make improper remarks, verbally abuse, ostracize, and belittle their subordinates. Research and media reports suggest that becoming a victim of leaders' insensitive treatment is a negative experience for employees, detrimental to their well-being and the efficiency of the organization. Mistreatment by leaders has been referred to in several ways, including interpersonal injustice (Greenberg, 1993), abusive supervision (Tepper, 2000), social undermining (Duffy, Ganster, \& Pagon, 2002), tyranny (Ashforth, 1994), and bullying (Hoel \& Cooper, 2001). Although each

\footnotetext{
${ }^{1}$ The first two authors contributed equally to this paper.
} 
conceptualization has subtle differences, they all involve employees' perceptions that some of their fundamental psychological needs are impeded by an authority figure (see Aquino and Thau (2009), for a review). Victimized employees receive the signal that they are not competent, worthy, and valued by the mistreating authorities; employees who are mistreated by leaders learn that they have little status in their work group (e.g., Aquino \& Douglas, 2003; Bies, 2001; Brockner et al., 1998; Tyler, 1999; Van Prooijen, Van den Bos, \& Wilke, 2002).

It may come with little surprise then, that mistreated employees respond negatively to leader mistreatment and are more likely to engage in deviant behavior, violating norms of considerate conduct (e.g., to be polite, to be respectful) and of efficient production (e.g., to comply with the supervisor's instructions, to be on time; Bennett \& Robinson, 2000). These norm violations have in common that they harm the well-being of the organization and its members (Bennett \& Robinson, 2000; Judge, Scott, \& Ilies, 2006). For instance, Duffy et al. (2002) found that employees who feel undermined by their supervisors were more likely to engage in both passive and active deviant work behaviors targeted towards the organization in general. Mitchell and Ambrose (2007) found that employees who feel abused by their supervisors were more likely to engage in deviant behaviors targeted towards the supervisor, coworkers, and the organization in general. In addition, Tepper et al. (2009) found a positive relationship between abusive supervision and organizational and supervisor-directed deviance, and this relationship was stronger when employees had a higher intent to quit.

The current paper proposes and tests empirically a theoretical model that further explains the relationship between leader mistreatment and workplace deviance. Through the integration of two theoretical perspectives (self-uncertainty and thwarted needs), we test a mediated-moderation model in which we expect the relationship between leader mistreatment and deviant employee behaviors to be stronger for employees who experience high levels of competence uncertainty. We also predict and test hostility as a mediator of the interactive leader mistreatment $\mathrm{x}$ competence uncertainty effect on deviant behaviors.

The model we develop in this paper addresses limitations of social exchange theory (SET; Homans, 1961), which is a typical explanation used to understand the effects of mistreatment on deviance (e.g., Bradfield \& Aquino, 1999; Duffy et al., 2002; Greenberg \& Scott, 1996; see Cropanzano and Mitchell (2005) for a review). This theory conceptualizes workplace relationships as interdependent and motivated by self-interest (Clark \& Mills, 1979). During the course of a relationship, the terms of social exchange are implicitly negotiated based upon the obligations each participant's actions generate. Obligations are treated in a quid pro quo manner according to the norm of reciprocity (Gouldner, 1960). Just as employees reciprocate positive treatment in a similarly positive way, so will employees retaliate and reciprocate harm received by agents of the organization by directing harm towards the organization and/or its agents (Skarlicki \& Folger, 1997).

If the norm of reciprocity is the behavioral principle guiding reactions towards leader mistreatment, then employees who are unjustly treated, abused, or otherwise mistreated by authorities should reciprocate with harmful behaviors. Yet, not all victims reciprocate harmful supervisor behaviors. The relationships between measures of leader mistreatment (e.g., injustice, abuse, undermining) and measures of employee deviance (e.g., workplace deviance, antisocial behaviors, 
counterproductive behaviors) are only modestly positive, and they vary across studies (for meta-analytic reviews, see Berry, Ones, \& Sackett, 2007; Cohen-Charash \& Spector, 2001; Colquitt, Conlon, Wesson, Porter, \& Ng, 2001). If one makes the assumption that the norm of reciprocity is a robust and universal principle of social interaction, (Axelrod, 1984; Becker, 1986; Blau, 1964; Homans, 1961), then it is puzzling that not all employees reciprocate mistreatment with deviant behaviors. Apparently, mistreatment is not equally salient to everybody. SET makes no explicit predictions about when mistreatment should become more or less salient, which we refer to as the salience problem of SET (e.g., Thau, Aquino, \& Wittek, 2007; Thau, Bennett, Mitchell, \& Marrs, 2009).

A second problem generated by past research is that even extended SET models addressing the salience problem fail to explain how mistreatment by leaders affects deviance (e.g., Duffy et al., 2002). Past studies have shown that mistreated employees were more likely to engage in deviance when they experienced uncertainty (Colquitt, Scott, Judge, \& Shaw, 2006; Thau, Aquino, \& Wittek, 2007), but given that uncertainty is such a broad construct we focus on self-uncertainty regarding the fundamental human need of competence (Deci \& Ryan, 1985) and test the intervening psychological process accounting for the effect. A critical step in understanding a phenomenon and advancing future research and theory building is to move from main effect to moderation to mediation-types of explanations (e.g., Fiske, 2004).

We address the two problems by retaining the core SET assumption that various kinds of leader mistreatment are signals that motivate reciprocity, but we extend the theory by making additional assumptions about the self's motivation and social cognition. We address the salience problem by applying a selfuncertainty perspective (De Cremer, Brebels, \& Sedikides, 2008; De Cremer \& Sedikides, 2005; Thau, Aquino, \& Wittek, 2007). Based on uncertainty management principles (Lind \& Van den Bos, 2002; Van den Bos \& Lind, 2002), the self-uncertainty perspective assumes that those who experience high levels of uncertainty pay relatively more attention to the way they are treated, rendering leader mistreatment a more salient experience, and leading to greater affective and behavioral reactions. Consequently, those who experience high levels of competence uncertainty will be more likely to reciprocate mistreatment by engaging in deviance. The second extension of SET we draw upon can answer the question of how mistreatment affects deviance. A thwarted needs perspective on leader mistreatment (e.g., Aquino \& Thau, 2009; Barclay, Skarlicki, \& Pugh, 2005; Thau, Aquino, \& Poortvliet, 2007) suggests that when people are denied fundamental needs (e.g., the acknowledgment of competence through mistreatment), they experience negative affective states like hostility. Hostile affect then explains why people engage in deviant behaviors. We integrate these two extensions of SET into a mediated-moderation model, in which employees who are highly uncertain about their competence are more likely to reciprocate leader mistreatment through deviance because they are more likely to experience hostile affect.

Our research contributes to the existing literature in several ways. First, whereas prior research has linked leader mistreatment to employee deviance, we extend such work by simultaneously answering the questions of when and why leader mistreatment results in employee deviance. Second, we address explanatory limitations of SET by extending it through an integration of self uncertainty and thwarted needs perspectives. Although there is an emerging body of research on the influence of self-uncertainty on reactions to mistreatment, the focus of this research has been predominantly cognitive by highlighting how the motivation to manage uncertainty steers attention towards leader 
mistreatment information. There are good reasons to believe, however, that the motives people pursue in social exchanges lead to an interplay between cognition and affect (Lawler, 2001). There is preliminary empirical support for the idea that mistreatment leads to negative affective reactions (Barclay et al., 2005; Barsky \& Kaplan, 2007). However, few studies have shown that these affective reactions explain why leader mistreatment motivates deviance. To address this gap, our paper considers competence uncertainty as a moderator of the relationships between mistreatment, hostility, and deviance. Thus, our primary contribution is in developing a theoretical model which takes into account the roles of motivation, cognition, and affect in social exchanges. Our research also furthers the study of self-uncertainty in organizational settings. To date, the majority of self uncertainty-based empirical work used laboratory experiments, and for that reason, we consider it important in our research to explore whether self-uncertainty effects generalize to the workplace (Colquitt et al., 2006; De Cremer \& Sedikides, 2005; De Cremer \& Van Hiel, 2008; De Cremer et al., 2008). Finally, we include both field and laboratory methods to test our conceptual model.

\section{Theoretical background and hypotheses}

The salience problem of SET describes the puzzle that once we assume that the norm of reciprocity is a robust principle guiding behavior in social exchanges, then SET cannot easily explain why everybody does not always reciprocate mistreatment. The self uncertainty perspective can address the salience problem by making the additional assumptions that leader mistreatment is not equally salient to everybody because not everybody is motivated to pay the same amount of attention to it. Attention towards mistreatment comes from the motivation to cope with self uncertainty. Selfuncertainty is an aversive, unpleasant, and challenging state to people, and coping with it is a major life challenge (Sedikides, De Cremer, Hart, and Brebels (2010), for a review).

Uncertainty management theory (Lind \& Van den Bos, 2002) suggests that information about how well one is treated serves the function of coping with self-uncertainty, so people who experience self-uncertainty are relatively more motivated to pay attention to mistreatment compared to those who are not experiencing self-uncertainty. Knowledge of treatment quality in such situations is useful "because it gives them the confidence that they will ultimately receive good outcomes and because it makes the possibility of loss less anxiety-provoking"' (Lind \& Van den Bos, 2002, p. 195).

A number of recent studies are consistent with a self-uncertainty account of reactions to mistreatment. Accordingly, people who experience self-uncertainty are more anxious in situations of risk (Colquitt et al., 2006), chronically compare themselves to others (Thau, Aquino, \& Wittek, 2007), and do not know whether others socially accept them (De Cremer et al., 2008). In a laboratory study, unjustly treated participants stole more pens when they were highly anxious in situations of uncertainty (i.e., risk averse, Colquitt et al., 2006). In a sample of health care workers, employees who were uncertain about their attitudes and opinions were more likely to engage in antisocial work behaviors when they perceived interactional injustice (Thau, Aquino, \& Wittek, 2007). Finally, in another laboratory study, De Cremer et al. (2008) found that participants' belongingness uncertainty intensifies the negative effects of procedural injustice on group identification. For the same amount of information about treatment quality to have a stronger effect on people who are uncertain about their self, the uncertain people need to have paid more attention to the information, which would render the information 
more salient and more influential on people as a result (Fiske \& Taylor, 2008).

\section{Competence uncertainty}

The fresh stream of research on self-uncertainty reveals an increased interest in investigating specific types of uncertainty regarding the self and the ways they intensify negative responses to mistreatment. Extending prior work, we examine the effects of competence uncertainty on the relationship between leader mistreatment and employee deviance.

Competence broadly refers to characteristics such as effectiveness, ability, and success (Elliot \& Dweck, 2005, p. 5). We define competence uncertainty as the self's certainty pertaining to these characteristics in the workplace. When people are uncertain about their competence ("I am not sure whether I do a good job"), managing that uncertainty becomes a relevant goal. They will therefore pay more attention to the way leaders treat them because such interpersonal treatment communicates how competent, worthy, and valued the employee is in the eyes of the authority ("This is how competent you are") (Aquino \& Douglas, 2003; De Cremer \& Tyler, 2005; Tyler \& Lind, 1992). Because treatment signals are relevant to the goal of managing uncertainty about one's competence, these signals should be paid more attention to, become more salient, and therefore, lead to stronger affective and behavioral reactions (Fiske \& Taylor, 2008). We predict:

Hypothesis 1. Employee competence uncertainty strengthens the positive relationship between leader mistreatment and employee deviance.

Before we continue to further lay out our theoretical model, it is relevant to note that our assumptions only pertain to variations in competence uncertainty, but not to variations in the extent to which people perceive their competence to be high or low (i.e., competence level). We believe that competence level and competence uncertainty are independent experiences of the self: Employees who feel that they are highly competent can be uncertain or certain about their competence just as employees who feel that they are not very competent can be very certain or uncertain about their competence. To empirically test the assumption that competence uncertainty and competence level are independent experiences of the self, we conducted a pilot study to distinguish competence uncertainty from constructs measuring perceptions of competence levels (e.g., self-efficacy, self-esteem).

The self-uncertainty perspective argues that leader mistreatment should be motivationally more relevant for employees high rather than low in competence uncertainty. We do not believe that there are equally clear arguments for the motivational relevance of leader mistreatment for individuals high and low in competence levels. For example, one way to operationalize a person's perceptions of their competence levels is through measures of self-esteem. Self-esteem can be defined as the overall value one places on oneself as a person (Harter, 1990). There are contradictory assumptions in the literature about whether mistreatment is motivationally more relevant for low (high) self-esteem individuals, and the findings pertaining to this area of research are inconsistent as well (Baumeister, Campbell, Krueger, \& Vohs, 2003; Ferris, Brown, Lian, \& Keeping, 2009; Kernis, 2005). It is outside the scope of our paper to fully address the debate around competence level and reactions to mistreatment in our paper. However, we statistically control for the interaction between mistreatment and variables assessing perceptions of competence level in Study 1, 2, and 3 to account for the possibility that these interactions influence the predicted relationships. 
Extant research has revealed a range of negative employee behaviors that result from leader mistreatment. Implicit in this literature is the idea that negative affective states are an important part of the causal chain from some type of leader mistreatment to subsequent reactions. Most generally, research on deviance describes targets of unwarranted interpersonal offenses as experiencing such "hot," intense, affective states and seeking to resolve these sentiments by adjusting their behaviors (i.e., balancing the scales via deviance). When employees are mistreated, it serves as a signal that they are not thought of as competent, valued, and respected. However, having one's competence affirmed by others is a fundamental need (Aquino \& Douglas, 2003; Deci \& Ryan, 1985; White, 1959); essentially everybody wants to be acknowledged as being competent. This assumption can explain why mistreatment is generally an aversive experience which, when paid attention to, should result in intense negative affective reactions (Aquino \& Thau, 2009).

Prior theoretical and empirical work suggests that individuals are particularly likely to experience hostility in reaction to leader mistreatment. An outward-focused affective state, hostility tends to arise when an individual is confronted with a serious or threatening situation (Smith, Haynes, Lazarus, \& Pope, 1993), including a demeaning offense or harmful action (Lazarus, 1991). It is especially likely when the individual can attribute responsibility to and blame another for the unpleasant situation (Smith et al., 1993). Consistent with the notion that mistreated employees may feel their status is threatened and blame their leader, a recent meta-analysis by Barsky and Kaplan (2007) found that state negative affect was positively correlated with distributive, interpersonal, and procedural injustice perceptions. More specifically, prior research has shown abusive supervision is positively associated with negative affective reactions (Tepper, Duffy, Henle, \& Lambert, 2006) and hostile reactions have been associated with threats to self-esteem (Baumeister \& Boden, 1998).

Consistent with the logic leading up to Hypothesis 1, we posit that uncertainty will reinforce the effects of leader mistreatment, and thus, leader mistreatment should reveal a stronger influence on hostility when people are uncertain about their competence. Recent studies have provided some evidence that uncertainty about one's self-concept strengthened the relationship between unfair treatment and negative affective reactions (De Cremer \& Sedikides, 2005; Van den Bos, 2001). Similarly, we expect that competence uncertainty will positively moderate the effect of leader mistreatment on hostility.

Hypothesis 2. Employee competence uncertainty strengthens the positive relationship between leader mistreatment and employee hostility.

The experience of negative affective states, like hostility, alerts people to the possibility that their current situation is undesirable and problematic, and their surge in negative energy both motivates and facilitates taking action to improve their situation. One way in which individuals experiencing strong negative affective states at work actively seek to resolve their work issues is to withdraw, sometimes permanently by leaving their organization (Pelled \& Xin, 1999). Another manifestation of unpleasant affect is harmful behavior. Outward-focused negative emotional states, such as hostility, are related to retaliatory impulses and directing action against a perpetrator (Barclay et al., 2005). Lee and Allen (2002) found that different kinds of negative affective experiences were significantly associated with interpersonal- and organizational- 
related workplace deviance.

Various perspectives suggest that leader mistreatment affects harmful employee behaviors through employees experiencing hot, intense affective states, like hostility. Indeed, negative affective experiences are expected to result from unfavorable interactions with others and will detrimentally affect one's subsequent behaviors (Tice, Baumeister, \& Zhang, 2004). In one of the few existing studies on the role of affect in explaining harmful employee behaviors, Barclay et al. (2005) found that hostility and irritation mediated the relationship between fairness perceptions and retaliation.

Applied to our question of how leader mistreatment relates to deviance, Lind and Van den Bos (2002) summarized our perspective succinctly: "when treatment is unfair or perhaps when even moderate levels of unfairness are particularly threatening in the face of great uncertainty, that negative affect drives people to frankly competitive actions in which harming the organization is as much as a goal as protecting the self" (p. 196). Although the links between mistreatment, uncertainty, negative affective states, and harmful employee behaviors can be traced theoretically, there is no direct empirical evidence for this prediction, perhaps because affective states have been given little attention in SET-based models of mistreatment and harmful behaviors. Barclay and her colleagues (2005) assessed the literature as follows: "although previous justice theories and research suggest emotions are part of the relationship between the experience of injustice and the tendency to retaliate ... little empirical research has examined the mediating role of emotions" ( $p$. 629).

Our research closes this gap, and together with the rationale provided for Hypothesis 2, we predict that the negative affective state of hostility mediates the leader mistreatment $\mathrm{x}$ competence uncertainty interaction on deviance. Employees experiencing more competence uncertainty will be more likely to react deviantly to mistreatment because their uncertainty causes more intense hostility.

Hypothesis 3. Hostility mediates the relationship between the leader mistreatment x competence uncertainty interaction and employee deviance.

\section{Overview of studies}

We conducted one pilot study, four field studies (Studies 1-4), and one laboratory experiment (Study 5) to test our theoretical model (see Fig. 1). In each substantive study, in addition to testing our theoretical model, we empirically examined the distinctiveness of the competence uncertainty construct. In the pilot study we developed the items and provided convergent and discriminant validity evidence for competence uncertainty, using confirmatory factor analyses. We provide information on measurement validity in Study 1-4 as well. In the first two studies, we tested the interaction between leader mistreatment and competence uncertainty on deviance. Specifically, in Study 1, we examined the interaction between abusive supervision and competence uncertainty on organizational deviance while controlling for generalized self-efficacy using a broad cross-section of US employees. In Study 2, we constructively replicated Study 1 by assessing interpersonal injustice as our measure of leader mistreatment and antisocial behavior as our dependent variable. Building on Study 1, we used a multisource approach with coworkers providing antisocial behavior ratings of the focal employees, and we controlled for job-specific self-efficacy in a sample of US employees from several different 
organizations. In the next three studies, we tested our complete mediated-moderation model. Specifically, in Study 3, a representative sample of Dutch employees provided data on interpersonal injustice, competence uncertainty, hostility, and antisocial behavior, and we tested our theoretical model while controlling for both generalized self-efficacy, selfesteem, and their interactions with interpersonal injustice. In Study 4, we used a similar approach as in Study 2 by utilizing coworkers to provide ratings of the focal employee's organization- and supervisor-directed deviance. In addition, we controlled for social desirability and trait negative affect while testing the mediated-moderation model with a sample of US employees from different organizations. Finally, in Study 5, a lab experiment, we manipulated leader mistreatment and competence uncertainty, measured hostility and deviance, and found support for our mediated-moderation model. In what follows, we provide information regarding the methods and results for the pilot study and the five hypothesestesting studies.

\section{Pilot study}

Before testing our hypotheses, we must first distinguish competence uncertainty both theoretically and empirically from constructs measuring variations in perceived competence levels, such as self-efficacy and self-esteem. We already defined self-esteem as the overall value a person places on oneself. Generalized self-efficacy is defined as "one's estimates of one's capabilities to mobilize the motivation, cognitive resources, and courses of action needed to exercise general control over events in one's life" (Judge, Locke, Durham, \& Kluger, 1998, p. 19). Bandura (1997) highlights

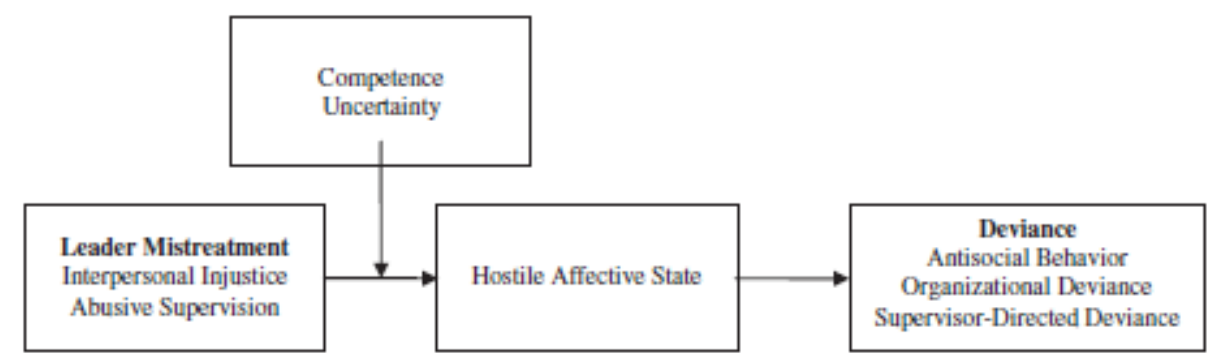

Fig 1. Mediated-moderation model of the relationship between leader mistreatment and employee deviance.

task-specific self-efficacy, which has the same definition but refers to a specific task or domain. Although there are similarities between competence uncertainty, as we have defined it, and competence level constructs, we believe that competence uncertainty is conceptually distinct through its explicit focus on uncertainty. Whereas self-efficacy and selfesteem refer to more global perceptions about one's capabilities and sense of self in positive or negative terms (i.e., selfperceived competence levels), competence uncertainty relates specifically to how uncertain one is about his/ her competence at work.

Given that the theoretical basis for our predictions relies on uncertainty, it is critical to differentiate competence uncertainty from related constructs not only conceptually, but empirically as well. Therefore, we examined whether there was evidence of discriminant validity between our measure of competence uncertainty and the competence level constructs. Participants assessed their competence uncertainty, generalized self-efficacy, and self-esteem, and we conducted confirmatory factor analyses to determine whether responses to our measure of competence uncertainty were 
empirically distinct from related established scales.

\section{Participants and procedure}

Invitations to participate in this study were emailed to 346 students who had previously indicated that they would be interested in participating in research conducted by a Dutch psychology department. The invitation email contained an explanation of the study and provided a link to a web page with a survey assessing the variables of interest. After 2 weeks, we sent a reminder email containing the same web link. A total of 99 employed students voluntarily took part in the survey. The average age of the participants was 44.02 years old, and $51 \%$ of them were female.

\section{Measures and measurement model}

We created a four-item measure of competence uncertainty (uncertainty about a person's effectiveness, ability, and success; see Elliot \& Dweck, 2005). Participants responded to a seven-point Likert-type scale $(1=$ not at all true, $7=$ very true) in terms of how well each statement described their experiences at work: "I am uncertain whether I am competent," "I am not sure if I do a good job," "I don't know whether other people think I am qualified," and "I don't know if I perform well at what I do" ( $\alpha .91)$.

\section{Generalized self-efficacy}

Participants completed a six-item measure of generalized self-efficacy (Judge, Bono, \& Locke, 2000). Sample items include, "I often feel like a failure" (reverse coded), and "I can handle the situations that life brings" ( $\alpha .88)$.

\section{Self-esteem}

We measured self-esteem using Robins, Hendin, and Trzesniewski's (2001) validated one-item measure "I have high self-esteem." Participants responded to this item on a seven-point Likert-type scale ( $1=$ not at all true, $7=$ very true).

\section{Measurement model}

The initial measurement model had two latent factors (i.e., competence uncertainty and self-efficacy/esteem) and 11 indicators (four for competence uncertainty and seven for self-efficacy/ esteem). Generalized self-efficacy and self-esteem were collapsed into one factor because a factor with only one indicator, like self-esteem, cannot be evaluated in a CFA. Competence uncertainty had significant relationships with both generalized self-efficacy $(r=-.42 ; p<.001)$ and self-esteem $(r=-.41 ; p<.001)$. The errors for the only two negatively worded items in the generalized self efficacy scale were allowed to correlate. The initial model fit the data well $\left(\mathrm{X}^{2}(42)=84.93, p<.001\right.$; SRMR $\left.=.09 ; \mathrm{CFI}=.97\right)$, and all indicators had significant $(p<.05)$ factor loadings. The alternative model, in which all 11 indicators loaded onto a single factor and the two negatively worded general self-efficacy indicators were allowed to correlate, fit the data poorly $\left(X^{2}(43)=514.16, p\right.$ $<.001 ; \mathrm{SRMR}=.18 ; \mathrm{CFI}=.72)$. The superior fit of the hypothesized measurement model is also reflected in a chi-square difference test that showed the two-factor model fit the data significantly better than the one-factor model $\left(X^{2}(1)\right.$ difference $=429.23, p<.001)$.

\section{Discussion}


The purpose of this pilot study was to assess whether our four- item measure of competence uncertainty is empirically distinct from conceptually related competence constructs assessing individual differences in competence levels. Although competence uncertainty was significantly correlated with the other constructs, confirmatory factor analyses revealed that a model in which competence uncertainty was a distinct construct fit the data best. This provides initial evidence for our claim that perceptions of competence uncertainty and perceptions of competence level are distinguishable experiences.

\section{Study 1}

\section{Method}

\section{Participants and procedure}

To recruit participants, we used Zoomerang.com, an online data collection service that provides researchers the opportunity to advertise their studies to adult online consumers. The panel of Americans to which Zoomerang.com advertised our study is largely comparable to those represented in the US Census in terms of age and annual household income, but females are slightly overrepresented (Zoomerang, 2005). The same panel of working adults has also been sampled by researchers in the medical sciences (Becker, Schwartz, Saris-Baglama, Kosinski, \& Bjorner, 2007) and organizational behavior (Thau et al., 2009).

Three hundred and sixty-nine consumers agreed to participate in our two-wave study in exchange for Zoomerang points towards future purchases. We collected responses to the independent and control variables at Time 1, and we collected data on deviance 10 days later to minimize percept-percept inflation. Of these participants, 95.1\% worked parttime, and $53.7 \%$ were male. Their average age was 42.7 years.

\section{Measures}

Abusive supervision. We used Mitchell and Ambrose's (2007) five- item-version of Tepper's (2000) abusive supervision scale to measure leader mistreatment. Respondents rated how frequently their immediate supervisor engages in abusive activities on a seven-point Likert-type scale ( 1 = never, 7 = always). Sample items include, "My supervisor ridicules me" and "My supervisor tells me I'm incompetent" ( $\alpha .95)$.

Competence uncertainty. We used the same measure that we included in the pilot study ( $\alpha .90)$.

Organizational deviance. We measured organizational deviance with 10 items (Bennett \& Robinson, 2000). Participants responded to a seven-point Likert-type scale for all deviance items ( $1=$ never, 7 = daily). Sample items include, "Taken property from work without permission," and "Come in late without permission" ( $\alpha$.87). We collected this measure 10 days after all other variables to minimize percept-percept inflation. 
Table 1

Means, standard deviations, and correlations among Study 1 va riables.

\begin{tabular}{|c|c|c|c|c|c|c|c|c|c|}
\hline Variables & M & $S D$ & 1 & 2 & 3 & 4 & 5 & 6 & 8 \\
\hline 1. Employee age & 42.64 & 14.43 & & & & & & & \\
\hline 2. Employee sex & .46 & .50 & -.10 & & & & & & \\
\hline 3. Organization tenure & 8.88 & 9.11 & $.46^{* *}$ & -.10 & & & & & \\
\hline 4. Generalized self-efficacy & 5.55 & 1.06 & $.11^{\circ}$ & .04 & -.06 & $(85)$ & & & \\
\hline 5. Abusive supervision & 2.13 & 1.43 & $-.12^{*}$ & -.09 & -.02 & $-31^{*}$ & $(.95)$ & & \\
\hline 6. Competence uncertainty & 1.91 & 1.13 & $-.18^{* *}$ & .01 & -.05 & $-.53^{* *}$ & $29^{\circ}$ & $(.90)$ & \\
\hline 7. Organizational deviance & 1.58 & 80 & $-.26 *$ & .00 & .07 & $-.28 *$ & $35^{*}$ & $34^{*}$ & $(.87)$ \\
\hline
\end{tabular}

Note: $N=367$. For employee sex, 0 denotes males, 1 denotes females. Reliabilities are on the diagonal in parentheses,

$p<.05$.

$\cdots p<.01$.

Control variables. We controlled for generalized self-efficacy (Judge et al., 2000) to account for the possibility that variations in competence level influence our predictions. Participants responded to a seven-point Likert-type scale $(1=$ not at all true, 7 = very true). Sample items include, "I often feel like a failure" (reverse coded), and "I can handle the situations that life brings" $(\alpha .85)$. We also controlled for the interaction between this variable and abusive supervision in our analyses to provide a more conservative test of Hypothesis 1. Although not of direct theoretical interest, certain demographic variables may affect the hypothesized relationships. Specifically, prior research suggests that employee age, gender and tenure can explain negative reactions to leader mistreatment (Aquino \& Douglas, 2003; Aquino \& Thau, 2009). We, therefore, included these employee characteristics as control variables.

Measurement model. Prior to testing our hypotheses, we conducted a CFA. The initial measurement model had four latent factors (i.e., abusive supervision, competence uncertainty, organizational deviance, and generalized self-efficacy) and 25 indicators (five items for abusive supervision, four items for competence uncertainty, 10 items for organizational deviance, and six items for generalized self-efficacy). Additionally, we allowed the errors of the only two negatively worded items for generalized self-efficacy to correlate. The resulting model had an adequate fit $\left(X^{2}(268)=1056.25, p<.001 ; S R M R=\right.$ $.07 ; \mathrm{CFI}=.90)$, and all indicators had significant $(p<.05)$ factor loadings. We also estimated a three-factor model that had the same structure as the previous model except that the competence uncertainty and self-efficacy items loaded on the same factor. This model had poor fit $\left(\mathrm{X}^{2}(271)=2164.70, p<.001\right.$; SRMR $\left.=.09 ; \mathrm{CFI}=.75\right)$. Finally, we estimated a onefactor model with all of the items loading onto a single factor. This model also had poor fit $\left(X^{2}(274)=6975.90, p<.001\right.$; $S R M R=.20 ; C F I=.39)$. A chi-square difference test showed that the four-factor model fit the data significantly better than both the three-factor model $\left(X^{2}(3)\right.$ difference $\left.=1108.45, p<.001\right)$ and the one-factor model $\left(X^{2}(6)\right.$ difference $=5919.65$, $p<.001)$.

\section{Study 1 results}

\section{Descriptive statistics}

Means, standard deviations, and correlations for the key variables appear in Table 1. 
Table 2

Results of hierarchical regression analysis for organizational deviance in Study 1.

\begin{tabular}{|c|c|c|c|}
\hline Variables & Step 1 & Step 2 & Step 3 \\
\hline Employee age & $-37^{\cdots}$ & $-.28^{\cdots}$ & $-.27^{\cdots \cdots}$ \\
\hline Employee sex & -.01 & .02 & .02 \\
\hline Organization tenure & $.24 \cdots$ & $.21^{\cdots}$ & $.20^{\cdots *}$ \\
\hline Generalized self-efficacy (GSE) & & -.05 & -.05 \\
\hline Abusive supervision (AS) & & $.25^{\cdots}$ & $.23^{\cdots}$ \\
\hline Competence uncertainty (CU) & & $.20^{* \cdots}$ & $.15^{*}$ \\
\hline AS $\times$ GSE & & & .00 \\
\hline $\mathrm{AS} \times \mathrm{CU}$ & & & $.19^{\cdots \cdots}$ \\
\hline$R_{\text {change }}^{2}$ & .11 & .15 & .03 \\
\hline Fchange & $15.44^{\cdots}$ & $23.85^{\cdots \cdot}$ & $8.32^{* *}$ \\
\hline$R_{\text {townl }}^{2}$ & .11 & .26 & .29 \\
\hline$R_{\text {adfurts d }}^{2}$ & .11 & .25 & .28 \\
\hline$F_{\text {tota }}$ & 15.44 & 25.10 & 18.55 \\
\hline
\end{tabular}

Note: For employee sex, 0 denotes males, 1 denotes females. Table presents Beta coefficients.

$p<.05$.

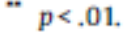

$\cdots p<.001$

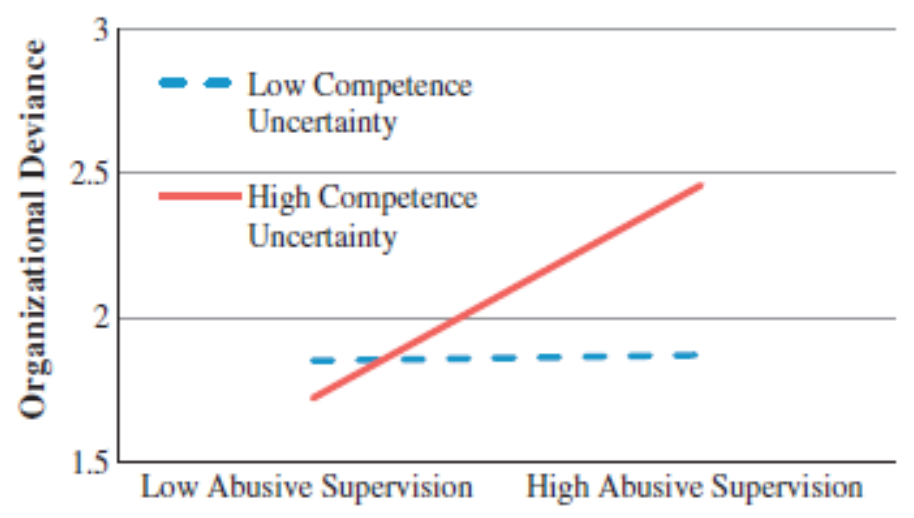

Fig. 2. Interaction of abusive supervision and competence uncertainty on organizational deviance (Study 1).

\section{Hypothesis test}

Hypothesis 1 predicted that employee competence uncertainty strengthens the positive relationship between leader mistreatment and employee deviance. The results presented in the third step of Table 2 show a significant, positive relationship between the abusive supervision $x$ competence uncertainty interaction and organizational deviance $(\beta=.19$, $p<.001$ ). Simple slopes analyses indicate that when employees' competence uncertainty was high (one SD above the mean), abusive supervision was more strongly related to ratings of organizational deviance $(ß=.22, p<.001)$ than when employees' competence uncertainty was low (one $S D$ below the mean; $\beta=.04, n s$ ). These analyses support Hypothesis 1 and indicate that the effect of leader mistreatment on employee deviant behavior becomes greater at higher levels of 
competence uncertainty (see Fig. 2). ${ }^{23}$

\section{Study 2}

\section{Method}

\section{Participants and procedure}

The sample consisted of 406 (213 focal employees and 193 coworkers) part- or full-time employees working in the United States and representing a variety of industries, including banking, defense, entertainment, government, health care, hospitality, manufacturing, and retail. Focal employees ranged in age from 18 to 65 , with a mean age of 24.49 years. Of the focal respondents, $51 \%$ were female, and $68 \%$ were employed full-time. Average tenure with their current organization was 2.71 years. In terms of race, 61\% were White, 15\% Hispanic, 6\% Asian, 3\% Black, 2\% Latino/a, 1\% Biracial, and 3\% reported "Other." Coworkers ranged in age from 18 to 65 , with a mean age of 27.58 years. The majority were female $(61 \%)$ and worked full-time $57 \%$. Their average organizational tenure was 3.59 years. In terms of race, $54 \%$ were White, 12\% Hispanic, 7\% Black, 4\% Latino/a, 3\% Asian, and 2\% Native American or "Other."

We extended an invitation to participate in this study to 385 junior- and senior-level undergraduate students attending a large university in the southeastern United States. We provided each student with a packet that included two instruction sheets, one for a focal employee and one for a coworker. These sheets provided general information about the study, web addresses for the associated version of the online survey, and a unique identification number to be used for matching respondent data anonymously. As an incentive, participating students received extra credit for their involvement. Focal employees completed the focal respondent survey assessing the independent variables (i.e., interpersonal injustice, competence uncertainty) and selected a coworker to rate the dependent variable (i.e., focal employee antisocial behavior) in a complementary online survey. Only students who were working part- (i.e., at least $20 \mathrm{~h}$ a week) or full-time were eligible to participate. Therefore, students who met this condition could serve as focal respondents, and those who did not could ask acquaintances fulfilling the requirement to be the focal employee. A total of 236 students volunteered to take part in the study. Thus, the response rate was 55\%. We utilized this snowball sampling method (e.g., Grant \& Mayer, 2009; Mayer, Kuenzi, Greenbaum, Bardes, \& Salvador, 2009; Skarlicki \& Folger, 1997) of gathering both focal employee and coworker ratings to reduce potential error caused by single-source bias.

\section{Measures}

Interpersonal injustice. We used Colquitt's (2001) four-item measure to assess leader mistreatment. On a seven-point Likert-type scale ( 1 = to a small extent, 7 = to a large extent), we asked respondents to rate how they are generally treated by their immediate supervisor. Sample items include, "Does your immediate supervisor treat you with dignity? (reverse

\footnotetext{
${ }^{2}$ The results from this study and the other studies remained essentially unchanged when we analyzed the data without the control variables.

3 Our dependent variable, employee deviance is strongly positively skewed across all field studies. We therefore performed Tobit regression (see Tobin (1958), for the development of this procedure; see Bierens (2005), for a recent account) to test the robustness of the OLS regressions; the results of the Tobit regressions lead to the same substantive conclusions.
} 
coded)" and "Does your immediate supervisor refrain from improper remarks or comments? (reverse coded)" ( $\alpha .95)$.

Competence uncertainty. We used the same measure and response scale as in Study $1(\alpha .90)$.

Antisocial behavior. We used seven items from Robinson and O'Leary-Kelly's (1998) measure of antisocial behavior to assess employee deviance. On a seven-point scale ( 1 = strongly disagree, 7 = strongly agree), respondents rated the degree to which the focal employee regularly engages in certain behaviors at work. Sample items include, "Deliberately bends or breaks a rule(s)," and "Does something that harms the organization or supervisor" ( $\alpha .92)$.

Control variables. We controlled for job-specific self-efficacy (Spreitzer, 1995) to test whether variations in competence level affect the predicted interaction. Participants responded to a seven-point Likert-type scale $(1=$ not at all true, $7=$ very true). Sample items include, "I am confident about my ability to do my job," and "I am self-assured about my capabilities to perform my work activities" ( $\alpha$.94). We also controlled for the interaction between this variable and interpersonal injustice in our analyses. As we did in Study 1, we controlled for several demographics such as employee age, gender, education level, and tenure that have been linked to negative reactions to leader mistreatment (Aquino \& Douglas, 2003; Aquino \& Thau, 2009).

\section{Measurement model}

We conducted and compared CFAs on our hypothesized measurement model and two alternative models prior to testing our hypotheses. The initial measurement model had four latent factors (i.e., interpersonal injustice, competence uncertainty, job-specific self-efficacy, and antisocial behavior) and 18 indicators (four items for interpersonal injustice, four items for competence uncertainty, three items for self-efficacy, and seven items for antisocial behavior). The resulting model had an adequate fit $\left(\mathrm{X}^{2}(129)=476.59, p<.001 ; \mathrm{SRMR}=.06 ; \mathrm{CFI}=.92\right)$, and all indicators had significant $(p<.05)$ factor loadings. We also estimated a three-factor model which had the same structure as the previous model except that the competence uncertainty and job-specific self-efficacy items loaded on the same factor. This model had insufficient fit $\left(X^{2}(132)=1001.43, p<.001 ; S R M R=.12 ; C F I=.82\right)$. Finally, we also estimated a one-factor model with all of the measures loading onto a single factor. This model also had poor fit $\left(\mathrm{X}^{2}(135)=3520.86, p<.001 ; \mathrm{SRMR}=.24 ; \mathrm{CFI}=.40\right)$. A chi-square difference test showed that the four-factor model fit the data significantly better than both the three-factor model $\left(X^{2}(3)\right.$ difference $=524.84, p<.001)$ and the one-factor model $\left(X^{2}(6)\right.$ difference $\left.=3044.27, p<.001\right)$.

\section{Study 2 results}

\section{Descriptive statistics}

Means, standard deviations, and correlations for the key variables appear in Table 3.

\section{Hypothesis test}

Hypothesis 1 predicted that employee competence uncertainty strengthens the positive relationship between leader mistreatment and employee deviance. The results presented in the third step of Table 4 show a significant, positive relationship between the interaction of interpersonal injustice and competence uncertainty and antisocial behavior $(\beta=$ $.19, p<.05$ ). Simple slopes analyses indicate that when employees' competence uncertainty was high (one SD above the 
mean), interpersonal injustice was more strongly related to ratings of antisocial behavior $(\beta=.45, p<.001)$ than when employees' competence uncertainty was low (one $S D$ below the mean; $\beta=.31, p<.001$ ). These data support Hypothesis 1 and indicate that the effect of leader mistreatment on employee antisocial behavior becomes greater at higher levels of competence uncertainty (see Fig. 3).

Table 3

Means, standard deviations, and correlations among Study 2 va riables.

\begin{tabular}{|c|c|c|c|c|c|c|c|c|c|c|}
\hline Variables & M & $S D$ & 1 & 2 & 3 & 4 & 5 & 6 & 7 & 8 \\
\hline 1. Employee age & 24.49 & 6.73 & & & & & & & & \\
\hline 2. Employee sex & .51 & .50 & -.02 & & & & & & & \\
\hline 3. Education level & 3.45 & .67 & $.38 *$ & -.04 & & & & & & \\
\hline 4. Organization tenure & 2.71 & 3.40 & $.67^{* *}$ & -.11 & $.22^{* *}$ & & & & & \\
\hline 5. Job-specific self-efficacy & 5.93 & 1.03 & .01 & .10 & .11 & .07 & $(.94)$ & & & \\
\hline 6. Interpersonal injustice & 2.41 & 1.33 & -.01 & -.02 & -.02 & .02 & $-.42^{* *}$ & $(.95)$ & & \\
\hline 7. Competence uncertainty & 1.94 & 1.31 & -.07 & -.10 & -.07 & -.11 & -.54 & $.43^{*}$ & $(.90)$ & \\
\hline 8. Antisodial behavior & 1.77 & .99 & -.01 & -.12 & -.08 & -.02 & $-.29^{* *}$ & $.40^{\circ *}$ & $.40^{\circ}$ & $(.92)$ \\
\hline
\end{tabular}

Note: $N=412$. For employee sex, 0 denotes males, 1 denotes females. Reliabilities are on the diagonal in parentheses.

$* p<.01$.

Table 4

Results of hierarchical regression analysis for antisodial behavior in Study 2.

\begin{tabular}{lccc}
\hline Variables & Step 1 & Step 2 & Step 3 \\
\hline Employee age & -.13 & -.15 & -.15 \\
Employee sex & -.12 & -.08 & -.09 \\
Education level & -.04 & -.02 & -.01 \\
Organization tenure & .05 & .12 & .10 \\
Job-specific self-efficacy (JSE) & & -.05 & -.09 \\
Interpersonal injustice (IPJ) & & $.22^{* *}$ & $.19^{*}$ \\
Competence uncertainty (CU) & & $.28^{\cdots}$ & .18 \\
IPJ $\times$ JSE & & & .01 \\
IPJ $\times$ CU & .03 & .21 & $.19^{*}$ \\
$R_{\text {change }}^{2}$ & 1.38 & $15.76^{* *}$ & .03 \\
$F_{\text {change }}$ & .03 & .24 & $.97^{*}$ \\
$R_{\text {toml }}^{2}$ & .01 & .21 & .27 \\
$R_{\text {adjustrd }}^{2}$ & 1.38 & 7.75 & 6.82 \\
$F_{\text {tatd }}$ & & & .23 \\
\hline
\end{tabular}

Note: For employee sex, 0 denotes males, 1 denotes females. Table presents Beta coefficients.

$p<.05$.

$p<.01$.

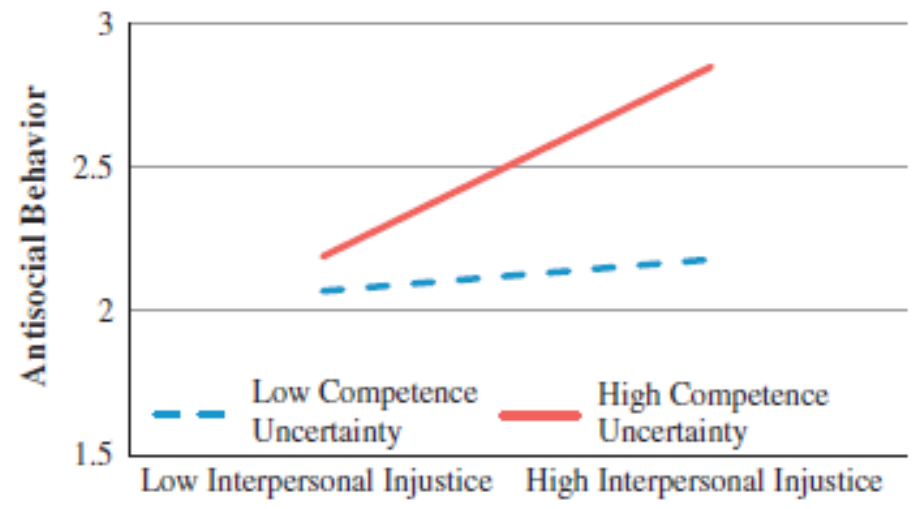

Fig. 3. Interaction of interpersonal injustice and competence uncertainty on antisocial behavior (Study 2). 


\section{Study 3}

\section{Method}

\section{Participants and procedure}

We invited 800 Dutch members of a research panel to participate in this study. For their participation, they received credit points that would allow them to receive certain gifts (e.g., tickets for the movies). A total of 507 employees filled out the questionnaire (a response rate of 63.3\%). However, because we only included respondents who indicated having a supervisor and working for at least $12 \mathrm{~h}$ a week, the actual number of respondents included in our analyses consisted of 412 employees. Fifty percent were male. Of the respondents, $2 \%$ had only lower education (primary school), $52 \%$ had secondary education (high school), $24 \%$ had with vocational education, $16 \%$ had a bachelor's degree, and $7 \%$ had a master's degree. The mean age was 44.02. The respondents worked, on average, for 11.41 years with their current organization and for 6.95 years in their current job. Twenty-one percent worked for the government, $75 \%$ worked for nongovernmental organizations, and $4 \%$ worked as temporary employees.

\section{Measures}

Interpersonal injustice. We used the same four-item measure and response format as used in Study 2 to assess leader mistreatment ( $\alpha .95)$.

Competence uncertainty. We used the same four-item measure and response format as used in the pilot study and Studies 1 and $2(\alpha .85)$.

Hostility. We measured hostility by averaging the responses to the six items from the PANAS-X hostility Scale (Watson \& Clark, 1994). On a seven-point Likert-type scale ( 1 =very slightly or not at all, 7 = extremely), participants rated the extent to which they had experienced feeling "irritable," "hostile," "disgusted," "scornful," "angry" and "loathing" at work during the past few weeks ( $\alpha .89)$.

Antisocial behavior. We used the same seven-item measure and response format as used in Study 2 to assess employee deviance ( $\alpha .85)$.

Control variables. We controlled for generalized self-efficacy and self-esteem. We used the same measure of generalized self-efficacy used in Study $1(\alpha .81)$ and self-esteem used in the pilot study. We also controlled for employee age, gender, education level, organization tenure, and job tenure. 
Table 5

Means, standard deviations, and correlations among Study 3 va riables.

\begin{tabular}{|c|c|c|c|c|c|c|c|c|c|c|c|c|c|}
\hline Variables & M & $S D$ & 1 & 2 & 3 & 4 & 5 & 6 & 7 & 8 & 9 & 10 & 11 \\
\hline 1. Employee age & 44.02 & 11.97 & & & & & & & & & & & \\
\hline 2. Employee sex & 1.49 & .50 & $-.27^{*}$ & & & & & & & & & & \\
\hline 3. Education level & 4.00 & 1.73 & -.01 & $-.19^{* *}$ & & & & & & & & & \\
\hline 4. Organization tenure & 11.41 & 10.91 & $.56^{* *}$ & $-.30^{* *}$ & .02 & & & & & & & & \\
\hline 5. Job tenure & 6.95 & 8.08 & $142^{* *}$ & $-.19^{* *}$ & -.02 & $.58^{* *}$ & & & & & & & \\
\hline 6. Interpersonal injustice & 2.15 & 1.25 & -.02 & .01 & .05 & $.10^{\circ}$ & .05 & $(.95)$ & & & & & \\
\hline 7. Competence uncertainty & 2.10 & 1.08 & $-.18^{* *}$ & .02 & -.06 & $-.13^{* *}$ & $-.13^{\circ}$ & $.16^{\circ}$ & $(85)$ & & & & \\
\hline 8. Self-esteem & 4.68 & 1.23 & .02 & $-.12^{\circ}$ & .24 & .00 & -.03 & -.02 & $-.24^{\circ}$ & & & & \\
\hline 9. Self-efficacy & 5.55 & .81 & $.20^{\circ}$ & -.09 & 21 & .04 & -.01 & -.18 & $-.41^{* .}$ & $.54^{* *}$ & $(81)$ & & \\
\hline 10. Hostility & 2.18 & 1.08 & $-.20^{\circ *}$ & .06 & -.03 & -.07 & -.07 & $.40^{\circ *}$ & $.22^{* *}$ & -.07 & -.24 & $(.82)$ & \\
\hline 11. Deviance & 1.64 & .78 & $-.18^{* *}$ & -.05 & .01 & .00 & -.07 & $.42^{*}$ & $.20^{\circ}$ & .02 & $-.19^{* *}$ & $.47^{\circ}$ & (.85) \\
\hline
\end{tabular}

Note: $N=412$. For employee sex, 1 denotes males, 2 denotes females. Reliabilities are on the diagonal in parentheses.

$p<.05$.

$\cdots p<.01$.

\section{Measurement model}

We conducted CFAs to test our hypothesized measurement model and compared it with two alternative models. The initial measurement model had five latent factors (i.e., interpersonal injustice, competence uncertainty, self-efficacy, hostility, and antisocial behavior; self-esteem could not be included as an independent factor because it was measured using a one-item measure so it was included with self-efficacy) and 28 indicators (four items for interpersonal injustice, four items for competence uncertainty, seven items for self-efficacy and self-esteem, six items for hostility, and seven items for antisocial behavior). The resulting model had an adequate fit $\left(\mathrm{X}^{2}(310)=1065.18, p<.001 ; \mathrm{SRMR}=.09 ; \mathrm{CFI}=.91\right)$, and all indicators had significant $(p<.05)$ factor loadings. We also estimated a four-factor model which had the same structure as the previous model except that the competence uncertainty and self-efficacy items loaded on the same factor. This model had insufficient fit $\left(X^{2}(314)=1719.48, p<.001 ;\right.$ SRMR $\left.=.12 ; C F I=.84\right)$. Finally, we also estimated a one-factor model with all of the measures loading onto a single factor. This model also had poor fit $\left(X^{2}(320)=5508.68, p<.001\right.$; $S R M R=.18 ; C F I=.40)$. A chi- square difference test showed that the five-factor model fit the data significantly better than the four-factor model $\left(X^{2}(4)\right.$ difference $\left.=654.30, p<.001\right)$ and a one-factor model $\left(X^{2}(10)\right.$ difference $\left.=4443.50, p<.001\right)$.

\section{Study 3 results Descriptive statistics}

Means, standard deviations, and correlations for the key variables appear in Table 5.

\section{Hypotheses tests}

We first tested whether leader mistreatment was more strongly related to deviance among respondents who were high, rather than low in competence uncertainty (Hypothesis 1). Consistent with our predictions, OLS regression analyses revealed a significant interaction effect of interpersonal injustice and competence uncertainty on antisocial behaviors ( $B$ $=.18, p<.001$; see Fig. 4a). Simple slope analyses (Aiken \& West, 1991) showed that the effect of mistreatment on antisocial behaviors was more positive among respondents high in competence uncertainty (1 SD above the mean; $\beta=$ $.48, p<.001)$ than among respondents low in competence uncertainty $(1 S D$ below the mean; $\beta=.13, p<.05)$. These results support Hypothesis 1 (see Fig. 4).

We hypothesized that the effects of the interaction of leader mistreatment (i.e., interpersonal injustice) and competence uncertainty on employee deviance (i.e., antisocial behavior) will be mediated by hostility. This implies testing 
whether there was an interpersonal injustice $\mathrm{x}$ competence uncertainty interaction on hostility (Hypothesis 2). The results are presented in Table 6. As shown in Table 6 , interpersonal injustice was positively related to hostility $(B=.39, p<.001)$. Relevant to the hypothesis test, there was a significant interaction of interpersonal injustice $x$ competence uncertainty interaction on hostility ( $\beta=.15, p<.01$; see Fig. $4 \mathrm{~b}$ ). Simple slopes analyses revealed that when competence uncertainty was low (one $S D$ below the mean), interpersonal injustice was significantly related to hostility $(B=.25, p<.01)$. However, when competence uncertainty was high, the relationship between interactional injustice and hostility was stronger (one $S D$ above the mean; $ß=.53, p<.001)$. The pattern of the interaction further supports Hypothesis 2.

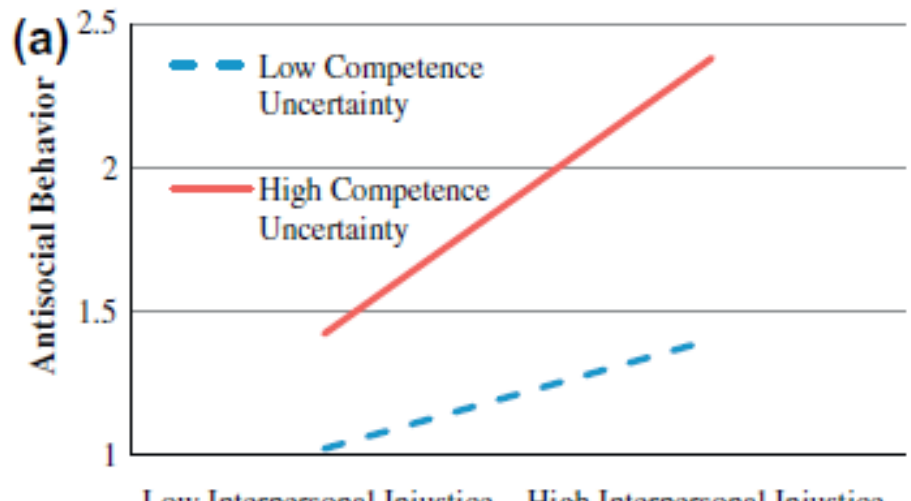

Low Interpersonal Injustice High Interpersonal Injustice

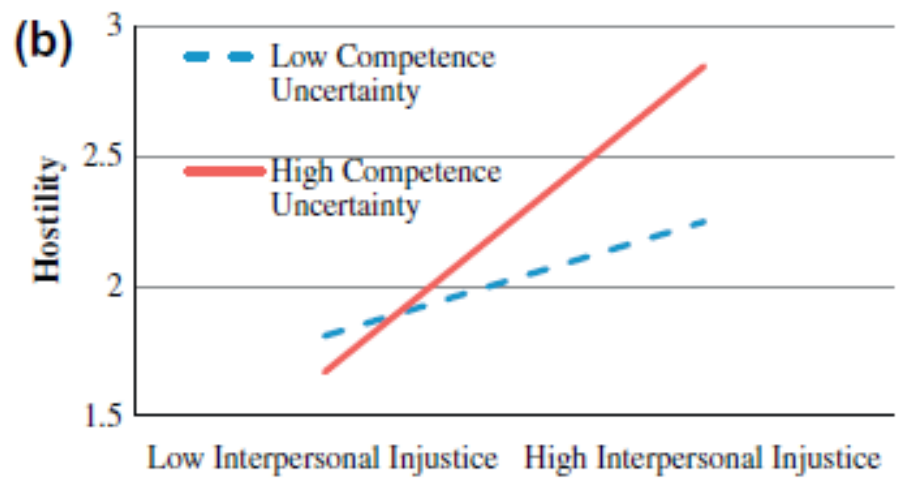

Fig. 4. Interaction of interpersonal injustice and competence uncertainty on (a) antisocial behavior and (b) hostility (Study 3 ).

Table 6 also shows that the interaction between competence uncertainty and interpersonal injustice on antisocial behavior was reduced in strength $(ß=.13, p<.01)$ when hostility was entered into the regression model. However, hostility was significantly related to employee antisocial behavior $(B=.37, p<.001)$. We next tested the significance of the mediated (i.e., indirect) effect of leader mistreatment on deviance, via hostility as a function of variations in the moderator variable (i.e., competence uncertainty). This implies estimating whether the product of the relevant regression coefficients (from the independent variable to the mediator and from the mediator to the dependent variable) varied at low and high levels of the moderator (competence uncertainty). Traditional significance tests rely on the assumption of normal distributions, but indirect effects (i.e., product terms) are often not normally distributed. We therefore followed Preacher, Rucker, and Hayes (2007) and bootstrapped 5000 samples. We then used the bootstrap estimates to calculate bias- 
corrected confidence intervals for the significance tests of the indirect effect estimates $(P)$ at high and low levels of the moderator. The results of these analyses revealed that the indirect effect of interpersonal injustice on antisocial behaviors, via hostility varied at high $(P=.13, p<.05)$ and low levels of competence uncertainty $(P=.06, p<.05)$. The difference between the two conditional indirect effects was statistically significant $(\Delta P=.07, p<.05)$, further supporting Hypothesis 3.

\begin{tabular}{|c|c|c|}
\hline Variables & Hostility & Deviance \\
\hline Employee age & $.14^{*}$ & $.16^{* *}$ \\
\hline Employee sex & .01 & $-.10^{\circ}$ \\
\hline Education level & .02 & .02 \\
\hline Organization tenure & .05 & .04 \\
\hline Job tenure & -.06 & -.03 \\
\hline$R_{\text {change }}^{2}$ & .04 & .05 \\
\hline$F_{\text {change }}$ & $3.14^{*}$ & $4.12^{\circ}$ \\
\hline Interpersonal injustice (IPJ) & $39^{\cdots}$ & $.16^{* *}$ \\
\hline Competence uncertainty (CU) & .07 & .02 \\
\hline Self-efficacy (SEF) & $-.15^{\circ}$ & -.01 \\
\hline Self-esteem (SES) & .05 & .03 \\
\hline$R_{\text {ehange }}^{2}$ & .20 & .11 \\
\hline Fonage & $23.81^{\cdots}$ & $12.10^{\cdots \cdots}$ \\
\hline IPJ $\times \mathrm{CU}$ & $.15^{* *}$ & $.13^{*}$ \\
\hline IPJ $\times$ SEF & .03 & -.04 \\
\hline IPJ $\times$ SES & -.04 & -.02 \\
\hline$R_{\text {change }}^{2}$ & .02 & .04 \\
\hline $\begin{array}{l}F_{\text {change }} \\
\text { Hostility }\end{array}$ & $3.50^{\circ}$ & $\begin{array}{r}5.65^{*} \\
37^{*}\end{array}$ \\
\hline$R_{\text {change }}^{2}$ & & .10 \\
\hline$F_{\text {change }}$ & & $54.00^{\cdots}$ \\
\hline$R_{\text {total }}^{2}$ & .26 & .30 \\
\hline$R_{\text {adfursted }}^{2}$ & .23 & .28 \\
\hline$F_{\text {totd }}$ & $10.63^{\cdots}$ & $12.17^{\cdots}$ \\
\hline
\end{tabular}

\section{Study 4}

\section{Method}

\section{Participants and procedure}

The sample consisted of 218 (114 focal employees and 104 coworkers) part- or full-time employees working in the United States and representing a variety of industries, including education, finance, food service, government, healthcare, hospitality, manufacturing, and retail. Focal employees ranged in age from 19 to 58 years, with a mean age of 25.11 years. Of the focal respondents, 53\% were female, and 55\% worked part-time. Average tenure with their current organization was 3.08 years. In terms of race, $64 \%$ were White, $17 \%$ Hispanic, $8 \%$ Black, $4 \%$ Native American, $3 \%$ Asian, $2 \%$ Biracial, and $3 \%$ reported "Other." Coworkers ranged in age from 18 to 61 years, with a mean age of 28.98 years. The majority were male (64\%) and worked full-time (72\%). Their average tenure was 4.33 years. In terms of race, $64 \%$ were White, $14 \%$ Hispanic, 9\% Black, 7\% Native American, 3\% Asian, 3\% Biracial, and 1\% reported "Other." All respondents finished high 
school, $67.5 \%$ of focal employees and $57.7 \%$ coworkers had completed at least some college, and $25.4 \%$ of focal employees and $26.9 \%$ of coworkers were college graduates.

We used the same data collection procedure as in Study 2. We extended an invitation to participate in this study to 232 junior- and senior-level undergraduate students attending a large university in the southeastern United States. A total of 114 students volunteered to take part in the study. Thus, the response rate was $49.14 \%$. Focal employees completed the focal respondent survey assessing the independent variables (i.e., abusive supervision, competence uncertainty, and hostility) and selected a coworker to rate the dependent variable (i.e., focal employee deviance) in a complementary online survey.

\section{Measures}

Abusive supervision. We assessed leader mistreatment with the same abusive supervision scale and response format as in Study 1, except we used the complete 15-item version of Tepper's (2000) measure ( $\alpha$.95).

Competence uncertainty. We measured competence uncertainty with the same four-item scale and response format as used in the pilot study and Studies 1-3 ( $\alpha .82)$.

Hostility. To measure hostility, we used the same six-item scale and response format as used in Study 3 ( $\alpha .82$ ).

Deviance. We measured organizational deviance with 11 items from Bennett and Robinson's (2000) scale ( $\alpha$.95) and supervisor-directed deviance with 10 items (Mitchell \& Ambrose, 2007). Sample items include, "Gossiped about his/her supervisor," and "Swears at his/her supervisor" $\alpha$.96). We used the same response format as used in Study 1 . We combined the two measures into a general measure of deviance because their correlation was high $(r=.88)$.

Control variables. We controlled for trait negative affect with Watson and Clark's 10-item measure, because employees high on this trait may be more likely to both experience leader mistreatment and react to it in a deviant manner (Aquino, Lewis, \& Bradfield, 1999). On a seven-point Likert-type scale (1 =very slightly or not at all, 7 = extremely), participants rated the extent to which they typically experience certain feelings in life in general including, "distressed" and "nervous" ( $\alpha .91)$. In addition, we controlled for social desirability with a shortened, 10-item version of the Mar- lowe-Crowne Social Desirability Scale (Strahan \& Gerbasi, 1972). Sample items include "I always try to practice what I preach" and "I have never deliberately said something to hurt someone's feelings" ( $\alpha$.74). Respondents rated both trait negative affect and social desirability items on a seven-point Likert scale. We included employee gender, age, and organization tenure as control variables. Additionally, we controlled for organizational position as it represents another type of status variable that may affect employee reactions to mistreatment.

\section{Measurement model}

We conducted a CFA on the self-report measures. The measurement model for self-report data included three latent factors (i.e., abusive supervision, competence uncertainty, and hostility) and 24 indicators (15 items for abusive supervision, four items for competence uncertainty, and five items for hostility). The three- factor solution produced an acceptable fit $\left(\mathrm{X}^{2}(249)=709.08, p<.001 ; \mathrm{SRMR}=.08 ; \mathrm{CFI}=.92\right)$. We compared this model to a one-factor model with all 
indicators loading onto a single factor $\left(\mathrm{X}^{2}(252)=1046.60, p<.001 ; \mathrm{SRMR}=.11 ; \mathrm{CFI}=.89\right)$, and a chi-square difference test showed that the three-factor model fit the data significantly better $\left(X^{2}(3)\right.$ difference $\left.=337.52, p<.001\right)$.

\section{Study 4 results}

\section{Descriptive statistics}

Means, standard deviations, and correlations for the key variables appear in Table 7.

Table 7

Means, standard deviations, and correlations among Study 4 va riables.

\begin{tabular}{|c|c|c|c|c|c|c|c|c|c|c|c|c|c|}
\hline Variables & $M$ & $S D$ & 1 & 2 & 3 & 4 & 5 & 6 & 7 & 8 & 9 & 10 & 11 \\
\hline 1. Employee age & 25.11 & 8.55 & & & & & & & & & & & \\
\hline 2. Employee sex & .47 & .50 & $-.24^{*}$ & & & & & & & & & & \\
\hline 3. Employee tenure & 3.08 & 3.98 & $59^{* *}$ & $-21^{\circ}$ & & & & & & & & & \\
\hline 4. Employee position & 1.42 & .82 & $31^{*}$ & -.01 & $.45^{\circ}$ & & & & & & & & \\
\hline 5. Employee social desirability & 4.84 & .92 & $.22^{*}$ & $-.19 *$ & $.19^{*}$ & .14 & $(.74)$ & & & & & & \\
\hline 6. Employee trait negative affect & 2.20 & 1.03 & -.08 & .11 & -.10 & .13 & $-.40^{\circ}$ & $(.91)$ & & & & & \\
\hline 7. Abusive supervision & 1.84 & 1.09 & $-.19^{\circ}$ & $35^{\circ}$ & -.05 & .03 & $-.28 *$ & $.25^{\circ}$ & $(.95)$ & & & & \\
\hline 8. Competence uncertainty & 2.11 & 1.19 & -.17 & $28^{*}$ & -.10 & .02 & $-.28^{* *}$ & $.31^{*}$ & $.53^{\cdots}$ & $(.82)$ & & & \\
\hline 9. Hostility & 1.98 & .94 & -.05 & $.28^{*}$ & -.09 & -.03 & $-.36^{* *}$ & $.37^{*}$ & $.41^{* *}$ & .38 & $(.80)$ & & \\
\hline 10. Organization-directed deviance & 1.83 & 1.14 & -.20 & $35^{\circ}$ & -.08 & .09 & $-.24^{\circ}$ & .12 & $.63^{\circ}$ & $.50^{\circ}$ & $.58^{\circ}$ & $(.95)$ & \\
\hline 11. Supervisor-directed deviance & 1.77 & 1.22 & -.20 & $39^{*}$ & -.09 & .09 & $-.27^{* *}$ & .04 & $.73^{*}$ & $.44^{*}$ & $.57^{*}$ & $.88^{\circ}$ & (.96) \\
\hline
\end{tabular}

Note: $N=104$. For employee sex, 0 denotes females, 1 denotes males. Reliabilities are on the diagonal in parentheses.

$p<.05$.

$\cdots p<.01$.

$\cdots p<.001$.

\section{Hypotheses tests}

We followed the same data-analytical strategy as in Study 3. We first tested whether leader mistreatment was more strongly related to both types of deviance among respondents who were high, rather than low in competence uncertainty. Consistent with our predictions, initial regression analyses revealed a significant interaction effect of competence uncertainty and leader mistreatment $(B=.24, p<.05$; see Fig. $5 a)$ on deviance. Simple slopes analyses showed that the effect of mistreatment on deviance was more positive among respondents high in competence uncertainty (1 SD above the mean; $\beta=.61, p<.001)$ than among respondents low in competence uncertainty (1 SD below the mean; $\beta=.31, p<$ .06). These results support Hypothesis 1.

Hypothesis 2 posited that competence uncertainty strengthens the positive relationship between leader mistreatment and hostility. The results in Table 8 reveal a significant interaction between abusive supervision and competence uncertainty on hostility ( $\beta=.30, p<.05$; see Fig. $5 b)$. Simple slopes analyses indicate that when competence uncertainty was high (one $S D$ above the mean), abusive supervision was more strongly related to employee hostility $(B=.25, p<.05)$ than when competence uncertainty was low (one SD below the mean; $\beta=-.14, n s$ ). This provides support for Hypothesis 2 and suggests that as competence uncertainty increases, the relationship between abusive supervision and hostility intensifies. 

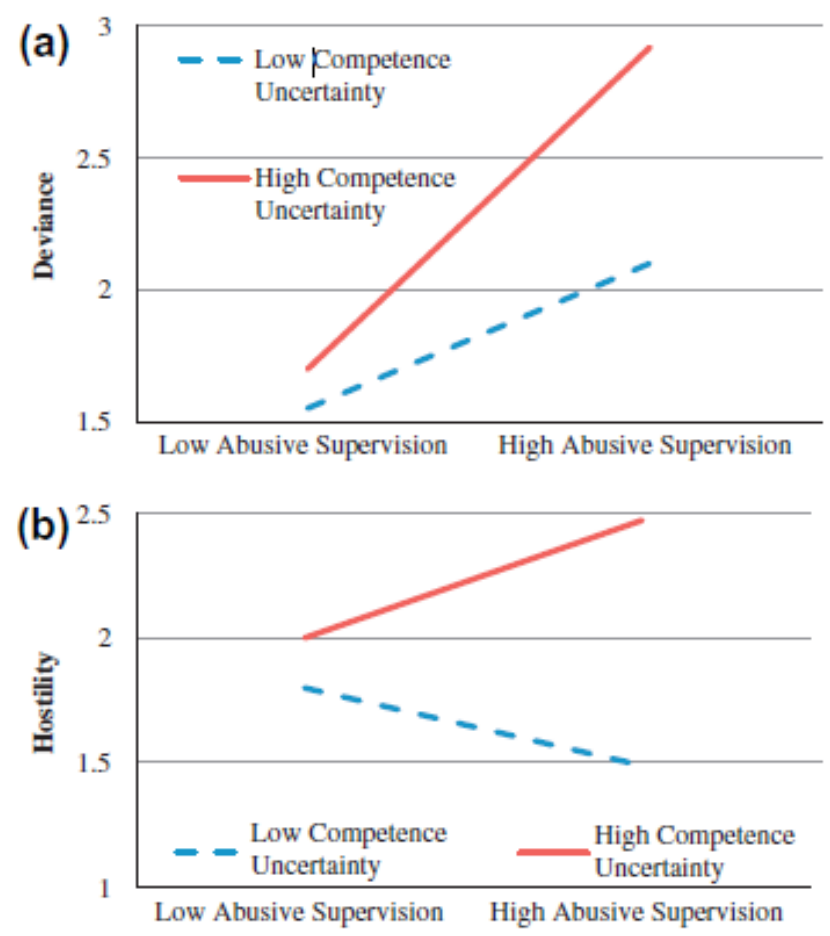

Fig. 5. Interaction of abusive supervision and competence uncertainty on (a) deviance and (b) hostility (Study 4 ).
Table 8

Results of mediated-moderation analyses for coworker-rated deviance in Study 4.

\begin{tabular}{|c|c|c|}
\hline Variables & Hostility & Deviance \\
\hline Employee age & .14 & -.14 \\
\hline Employee sex & .17 & .08 \\
\hline Employee tenure & -.05 & .01 \\
\hline Employee position & -.07 & .11 \\
\hline Employee social desirability & -.14 & -.01 \\
\hline Employee trait negative affect & $.30 *$ & -.10 \\
\hline$R_{\text {change }}^{2}$ & .25 & .24 \\
\hline$F_{\text {change }}$ & $4.43^{*}$ & $4.08 *$ \\
\hline Abusive supervision (AS) & .05 & 31 \\
\hline Competence uncertainty (CU) & .10 & .01 \\
\hline$R_{\text {change }}^{2}$ & .08 & .28 \\
\hline$F_{\text {change }}$ & $4.42^{\circ}$ & $22.21^{\cdots}$ \\
\hline $\mathrm{AS} \times \mathrm{CU}$ & $.30^{\circ}$ & .15 \\
\hline$R_{\text {ehonge }}^{2}$ & .05 & .03 \\
\hline $\begin{array}{l}F_{\text {change }} \\
\text { Hostility }\end{array}$ & $5.40^{\circ}$ & $\begin{array}{r}4.97^{\circ} \\
31^{\circ}\end{array}$ \\
\hline$R_{\text {ehange }}^{2}$ & & .06 \\
\hline$F_{\text {change }}$ & & $11.04 *$ \\
\hline$R_{\text {tomal }}^{2}$ & .38 & .61 \\
\hline$R_{\text {ndjusted }}^{2}$ & .30 & .56 \\
\hline Frotd & $5.02^{\cdots *}$ & $11.44^{\cdots \cdots}$ \\
\hline
\end{tabular}

Note: For gender, 0 denotes females, 1 denotes males.

$p<.05$.

$\cdots p<.01$.

$\cdots p<.001$.

Table 8 also shows that the interaction between competence uncertainty and abusive supervision was not significantly related to deviance $(B=.15, n s)$ when hostility was entered into the regression model. However, hostility was significantly related to deviance $(ß=.31, p<.01)$. The indirect effect analyses revealed that the indirect effect of abusive supervision on deviance, via hostility varied at high $(P=.07, p<.05)$ and low levels of competence uncertainty $(P=-.04, n s)$. The difference between the two conditional indirect effects was statistically significant as well $(\Delta P=-.11, p<.05)$. These results support Hypothesis 3.

\section{Study 5}

\section{Methods}

\section{Participants and procedure}

Eighty-nine students ( $60 \%$ females; Mean age $=19.86, S D=1.95)$ participated in an experiment at a behavioral research laboratory in exchange for course credit. When arriving to the laboratory, each participant was seated in an experimental cubicle equipped with a personal computer. All instructions to the participants were computerized. The participants learned that they would participate in a series of four unrelated studies. Participants then entered the first study on "communication styles and virtual teams." They were told that they and two other participants were randomly assigned roles in a virtual team, with them being selected as "team member B," and the remaining two participants as team members " $A$ " and " $C$," respectively. Participants were informed that, based on his year-long experience with virtual team work, a fourth person was selected as team leader. Participants were also told that this person was in the final year of his 
studies and was, in fact, working on his master's thesis. Participants learned that the task of their team was to generate solutions to improve the quality of teaching at their university. Participants read that past research with virtual teams had shown that these teams perform better (a) when they first generate individual suggestions before they eventually interact virtually and (b) when a leader coordinates and reviews the suggestions being made before giving further instructions for group interaction. This procedure would therefore also be followed in this study.

After reading about the procedure, participants were asked to generate three suggestions to improve the teaching quality at their university. They typed their suggestions into text boxes. When finished, participants pressed a "send" button, which supposedly sent the suggestions to the leader for review. Next, participants were asked to share some personal information so that the leader could get to know them better. Participants were asked to describe some of their hobbies and to describe themselves "as a person" in a brief paragraph. After submitting the information, a Window popped up showing connections being made to the university server. Next, a screen appeared which tracked the status of the information that the leader received from the team members. After the status tracker showed that all data were received, participants read that the team leader would subsequently go through the suggestions and the personal information of each team member.

\section{Competence uncertainty manipulation}

During the time the leader would go through the suggestions, participants were asked to start working on the second, unrelated study. This study was called a "life event inventory construction" study. This "study" included the competence uncertainty manipulation. Participants were asked to (a) briefly describe what the thought of being uncertain about their competencies arouse in them and (b) briefly describe what they think will physically happen to them when they feel uncertain about their competencies. This manipulation was adapted from Van den Bos's (2001) general uncertainty salience manipulation. Consistent with Van den Bos (2001), the control group participants described their thoughts and what will happen to them physically while watching TV. We also informed participants that the team leader would send them a message when he finished looking at all the information, and that this message would be made available to the participants when they completed the life event inventory study.

We assessed the effectiveness of the competence uncertainty manipulation in an independent study. Seventy-one undergraduate students were randomly assigned to either the competence uncertainty manipulation or to the control (TV) manipulation. To check for the effectiveness of the competence uncertainty manipulation, two coders who were blind to the conditions and to the aims of the study independently rated the extent to which participants' written protocols referred to competence uncertainty ( $1=$ not at all, 7 = very much) (see De Cremer et al., 2008; Van den Bos, 2001, for similar manipulation check procedures). There was high agreement between the raters' evaluations, $r=.90, p<.001$. An ANOVA showed that participants listed more thoughts and feelings about competence uncertainty in the competence uncertainty condition $(M=4.36, S D=1.32)$ than in the control condition $(M=1.32, S D=.83, F(1,69)=110.10, p<.001)$.

\section{Leader mistreatment manipulation}

After completing the competence uncertainty manipulation, participants continued with the virtual team study. Then 
the last screen of the study popped up, along with a message sent by the leader. In the leader mistreatment condition, the leader's message was:

" Hi team member B. I received your suggestions and I looked at them together with the other team member's suggestions. I also received your personal information and the paragraph you wrote about yourself. I have to say that I find your description pretty stupid. To be honest, I really don't appreciate your kind of people and I will let the other group members know this as well. Team leader."

In the control leader treatment condition, the leader's message was:

"Hi team member B. I received your suggestions and I looked at them together with the other suggestions. I also received your personal information and the paragraph you wrote about yourself. I look forward to working with you all. Team leader."

\section{Manipulation check for leader mistreatment manipulation}

Next, participants were told the first part of the virtual team study was completed and that the leader passed the suggestions through to the experimenters. Allegedly to further develop the virtual team methodology, we then asked participants to share their experiences in the virtual team environment. We ensured participants that we would not pass this information onto the team leader. The questions that followed assessed the manipulation checks of leader mistreatment perceptions. We asked participants (a) to what extent they felt that the team leader (a) treated them with respect (reverse coded), (b) acted rudely, and (c) is a mean person ( $1=$ not at all, $7=$ Very much) ( $\alpha .96)$.

\section{Hostility measure}

After completing the manipulation checks, we asked participants to tell us "how they felt during the virtual team experience." The same hostility items used in Study 3 and 4 were presented to participants $(1=$ not at all, $7=$ Very much) (a.95).

\section{Deviance measure}

Upon completion of the hostility scale, we thanked participants for sharing their virtual team experiences. What followed was the presentation of the dependent variable, which gave participants the opportunity to act deviantly (or compliantly) towards the team leader. Participants were told that the study was completed, and that they would have to wait for about $5 \mathrm{~min}$ for the other study to start. The participants also learned that the team leader had asked the experimenters to communicate to the participants that he is running another study in this laboratory for the completion of his master's thesis. Participants would support the team leader enormously through their participation, and participating would take them less than 5 min of their time (i.e., they could participate while waiting for the subsequent study, to make sure the entire research time did not go up if participants took part in the additional study).

Deviant behaviors can be defined as voluntary behaviors lacking the motivation to conform to normative expectations of the social context and in doing having the potential to negatively impact the organization's well-being (Bennett \& Robinson, 2000). Thus, refusing to participate in the study would, consistent with the definition of deviant behaviors, harm 
the well-being of an organizational member (the leader) and violate the normative expectation of contributing to a project that would not require an excessive amount of time and effort. Participants indicated their choice by indicating whether they would participate $(=0)$ (compliance) or not participate (deviance) and simply wait for the subsequent study to start $(=1)$.

\section{Study 5 results Manipulation check}

We found that the mistreatment manipulation was successful, participants in the leader mistreatment condition felt more mistreated $(\mathrm{M}=6.14, S D=.90)$ compared to participants in the control condition $(\mathrm{M}=2.10, S D=1.02 ; \beta=.90, p<$ $\left..001, R^{2}=.82\right)$.

\section{Hypotheses tests}

We first tested whether mistreated participants would more often reciprocate mistreatment by refusing to participate in the leader's study when competence uncertainty was manipulated compared to when it was not. Consistent with our predictions, in the competence uncertainty condition, leader mistreatment caused more participants to refuse to participate in the leader's project compared to the control condition. An OLS regression model ${ }^{4}$ showed that the interaction between mistreatment and competence uncertainty on deviance was significant and in the expected direction ( $(=.36, p<.05$; see Fig. 6a). Simple slope analyses showed that the effect of mistreatment on deviance was positive in the competence uncertainty condition $(B=.43, p<.01)$, but not in the control condition ( $B=.01, n s)$. These results support Hypothesis 1.

Next, we tested whether there was a similar interaction on hostility (Hypothesis 2). The results are summarized in Table 9. We found support for this prediction; there was a positive interaction effect between mistreatment and competence uncertainty on hostility ( $\beta=.28, p<.05$; see Fig. $6 \mathrm{~b}$ ). Simple slope analyses showed that the effect of mistreatment on hostility was stronger in the competence uncertainty condition $(\beta=.81, p<.001)$ than in the control condition $(\beta=.49, p$ $<.01)$.

Finally, we tested the mediated-moderation model predicted by Hypothesis 3. Table 9 shows that the interaction between mistreatment and competence uncertainty was no longer significant ( $(=.27, n s)$ when hostility was entered in the regression model, but hostility was significant $(B=.35, p<.05)$. As in Study 3 and 4 , we again performed an indirect effect analyses, which showed that the indirect effect of the mistreatment, via hostility, varied as a function of the competence uncertainty condition $(P=.28, p<.05)$ compared to the control condition $(P=.17, p<.05)$. The difference between the two conditional indirect effects was statistically significant $(\Delta \mathrm{P}=.11, p<.05)$. These results support Hypothesis 3.

\footnotetext{
${ }^{4}$ In Study 5's data, consistent with the OLS results reported in the main text, the interaction between leader mistreatment and competence uncertainty on deviance using probit regression was $b=1.08, p 6.05$ without hostility entered into the model, and $b=$ $84, n s$ with hostility $(b=.28, p<.05)$ entered in the model. The overall probit regression model explained $12 \%$ of the variance (Pseudo$\left.{ }^{\mathrm{R} 2}\right), \operatorname{LR~}^{2}(d f=4)=14.94$, $p<.01$.
} 

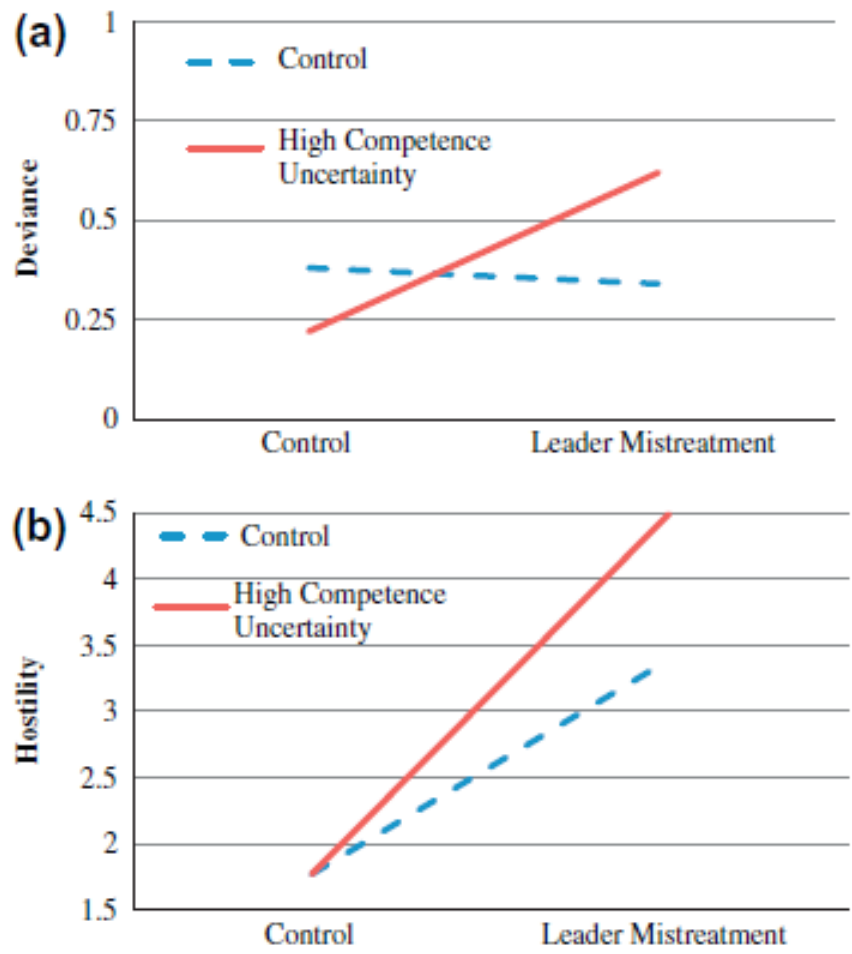

Table 9

Results of mediated-moderation analyses for deviance in Study 5.

\begin{tabular}{|c|c|c|}
\hline Variables & Hostility & Deviance \\
\hline Leader mistreatment ( $0=$ control condition) & $.48 \cdots$ & -.16 \\
\hline Competence uncertainty ( $0=$ control condition) & .00 & -.13 \\
\hline$R_{\text {Ehange }}^{2}$ & .46 & .06 \\
\hline$F_{\text {change }}$ & $36.55 \cdots$ & 2.62 \\
\hline Leader mistreatment $\times$ competence uncertainty & $.28^{\circ}$ & .27 \\
\hline$R_{\text {ethange }}^{2}$ & .03 & .04 \\
\hline $\begin{array}{l}F_{\text {change }} \\
\text { Hostility }\end{array}$ & $4.25^{\circ}$ & $\begin{array}{r}4.03^{\circ} \\
.35^{\circ}\end{array}$ \\
\hline$R_{\text {Ehange }}^{2}$ & & .06 \\
\hline$F_{\text {change }}$ & & $6.26^{*}$ \\
\hline$R_{\text {tounl }}^{2}$ & .49 & .16 \\
\hline$R_{\text {affurst d }}^{2}$ & .47 & .12 \\
\hline Fratd & $26.70^{\cdots}$ & $4.08^{*}$ \\
\hline
\end{tabular}

$p<.05$.

$* 0.01$.

$\cdots p<.001$.

Fig. 6. Interaction of leader mistreatment and competence uncertainty on (a) deviance and (b) hostility (Study 5).

\section{General discussion}

In this manuscript we presented a pilot study, four field-based survey studies, and one lab experiment to test our proposed mediated-moderation model. Specifically, we drew on self-uncertainty and thwarted needs perspectives to extend SET-based approaches to understand when and why leader mistreatment is associated with employee deviance. The pilot study showed that competence uncertainty can be empirically distinguished from constructs that assess perceptions of one's competence level (e.g., self-esteem, self-efficacy). In Study 1 and 2, we found support for the interaction between leader mistreatment and competence uncertainty on deviance, such that the positive relationship between leader mistreatment and employee deviance was stronger when competence uncertainty was high rather than low. We replicated the pattern of this interaction as well in Studies 3-5. Moreover, in Study 3-5 we found support for our mediated-moderation model in which hostility mediated the interactive effect of leader mistreatment and competence uncertainty on deviance. Study 5 was a laboratory experiment in which we manipulated leader mistreatment and competence uncertainty, providing evidence for causality. The five studies provide support for our theoretical model using different measures of leader mistreatment and deviance, utilizing multi-source data in two of the studies, providing construct validity evidence for our measure of competence uncertainty, including data from working adults from the US and Europe, and using an experiment with random assignment to allow for causal conclusions.

It is noteworthy that in Studies 1-3 we statistically controlled for constructs measuring perceptions of competence levels. Our results were robust over and beyond the potential influence of these constructs. We also tested for the possibility that competence level interacts with leader mistreatment to predict deviance; we did not find support for this 
possibility in our paper. Instead, we consistently found support for the predicted relationships based on the integration of the self-uncertainty and thwarted needs perspectives. The results have a number of implications for theory and practice, which we discuss below.

\section{Implications for an extension of SET to explain the mistreatment- deviance relationship}

Traditionally, SET has been the theoretical lens through which the effects of leader mistreatment on employee deviance have been examined (e.g., Bradfield \& Aquino, 1999; Duffy et al., 2002; Greenberg \& Scott, 1996). Although SET is useful to explain why there is a positive relationship between mistreatment and harmful behaviors, it is limited because it cannot explain when leader mistreatment becomes more or less salient to employees (Thau, Aquino, \& Wittek, 2007; Thau et al., 2009). Moreover, the intervening psychological process by which salient mistreatment affects deviance was also unexplored by past research. Recently, however, investigators have begun to approach the connection between leader mistreatment and employee deviance from a self-uncertainty and a thwarted needs perspective (Colquitt et al., 2006; Thau, Aquino, \& Poortvliet, 2007; Thau, Aquino, \& Wittek, 2007). We sought to extend this work by integrating these two streams of research to provide a more complete explanation for when and why leader mistreatment is related to employee deviance. Specifically, we presented a model of deviance that predicts that when an employee is uncertain about his or her own competence, leader mistreatment will have a larger effect on that employee's hostile reactions and ultimately, his or her deviant behavior. We theorized based on uncertainty management principles that when employees are unsure about their competence, managing that uncertainty becomes a relevant goal and that information about how well or poorly one is treated by authorities addresses that goal. When a specific kind of information is personally relevant, it becomes more salient in a given situation and has a greater influence on people's affect and behavior (Fiske \& Taylor, 2008). This explains why the relationship between leader mistreatment and hostility and deviance was more strongly positive for employees high rather than low in competence uncertainty. In sum, although SET explanations for the effects of leader mistreatment have been useful, the results of our studies presented support the use of a more complete theoretical perspective for the examination of potential mediators and moderators. Our study underlines the explanatory limits of SET as an explanation for deviant behaviors, and future research is needed to point out and investigate these limitations more thoroughly.

Implications for the role of uncertainty in extensions of SET

The mistreatment $x$ self-uncertainty interactions we found support the idea that people pay more attention to the same amount of mistreatment when they experience high competence uncertainty because the uncertainty people experience makes the mistreatment information personally relevant. The mistreatment becomes more salient as a result and has a greater impact on affective and behavioral reactions. Whereas this salience effect has been extensively discussed in the social psychological literature (Fiske \& Taylor, 2008), the positive zero-order correlations between competence uncertainty and mistreatment in our data may also suggest that uncertainty influences the amount of mistreatment one perceives. Possibly, there are two different kinds of salience effects in our data, and it has been noted previously that these effects are not mutually exclusive (Guido, 2001). Since we statistically controlled for the main effects of 
mistreatment and competence uncertainty in our analyses, we feel confident that we provided a fair test for the salience effect that is central to our theoretical formulation.

It is possible to further extend our theoretical formulation by extending it with the inconsistent literature on competence levels and reactions to mistreatment (Baumeister et al., 2003; Ferris et al., 2009; Kernis, 2005). Briefly, models assuming a self-verification motive suggest that employees low in self-perceived competence react positively (or at least not negatively) when they receive treatment that signals that they are not competent (e.g., Wiesenfeld, Swann, Brockner, \& Bartel, 2007). In contrast, models assuming a self-enhancement motive (e.g., Sedikides \& Strube, 1995) could predict the opposite-those low in self-esteem may be needier of positive treatment and react more negatively when they are mistreated. Perhaps these inconsistent findings could be explained by considering the role of competence uncertainty (see Kernis, 2005, for a similar argument for the role of self-esteem stability).

\section{Implications for the role of affect in extensions of SET}

The strong support we found for the affective state of hostility as a mediator in the well-established link between mistreatment and deviance should also reinforce Lawler and Thye's (1999) decade-old call to elaborate and improve upon social exchange theory by integrating it with the affect and emotions literature. Traditionally, social exchange theory assumes individuals to be self-interested, rational, and affectively vacuous informationprocessors (Lawler, 2001; Lawler \& Thye, 1999). Lawler's extension of social exchange theory acknowledges human nature as more social, expressive, and emotionally complex (Lawler, 2001). Accordingly, individuals have involuntary affective reactions to exchanges in which they are involved. The interplay it suggests between rational and nonrational, or affective processes stays true to the rational, instrumental foundation of traditional social exchange.

Both the traditional and affective theory of social exchange imply that deviant behavior is a result of instrumental motivation. Generally, rational individuals act out in a desire "to reconcile the disparity by repairing the situation, restoring equity, or improving the current situation" (Robinson \& Bennett, 1997, p. 18). For instance, employees feeling underpaid may attempt to balance the scales by stealing (Greenberg, 1990; Greenberg \& Scott, 1996) or working less by taking excessively long breaks (Lee \& Allen, 2002).

Past research recognized, though, that there is another motive to engage in deviance, one which is more affective than cognitive and which is less easily explained by current social exchange perspectives. Expressive motivation for deviance is "a need to vent, release, or express one's feelings of outrage, anger, or frustration" (Bennett \& Robinson, 1997, p. 18). A hot and intense affective reaction to mistreatment, like hostility, may result directly in a hot behavioral response. Our findings highlight expressive reasons for engaging in deviance, but future research is needed to identify when instrumental or expressive motives are more or less relevant in explaining employee deviance.

\section{Practical implications}

Given the significant consequences of employee deviance to organizations, knowledge about when and how it is related to leader mistreatment may have significant practical implications. Managers need to be aware that not every employee 
will react the same way to disrespectful or abusive treatment. Those employees who are uncertain about their ability to experience and exhibit competence at work are most sensitive to such behavior and more likely to react to it with deviance. These individuals may be dispositionally predisposed to be uncertain about their competence, but the manipulation of competence uncertainty in Study 5 also suggests that competence uncertainty can be temporarily experienced. It is possible that organizational situations such as change, performance feedback, or starting a new role are some factors that can make employees temporally uncertain about their competence. No matter the reason, managers must be sensitive to such individuals as they are likely looking for approval from organizational leaders to validate their competence and worth. If such individuals feel abused or unfairly treated, they will be more likely to engage in deviant behavior directed towards the organization in general and sometimes towards the offending manager or other employees. Managers may try to limit employees' sensitivity and negative affective and behavioral reactions to mistreatment by providing subordinates with feedback in a respectful and constructive manner as well as opportunities to utilize and develop their skills and other competencies. It may also be helpful for managers to recognize that it is when employees experience negative affect such as hostility, that they are most likely to act in deviant ways.

\section{Strengths, limitations, and future directions}

The current paper is characterized by a number of strengths, including an integrative theoretical approach to examine the relationship between leader mistreatment and employee deviance as well as a five-study design with multiple operationalizations of the key constructs in diverse samples using both self-report and coworker ratings of deviance in the field and lab. Despite these strengths, some limitations of this research are important to note.

One potential limitation of the current research is that Studies 1 and 3 utilized only self-report data. It is possible that another variable, such as social desirability, biased the findings (Podsakoff, MacKenzie, Lee, \& Podsakoff, 2003). In an attempt to limit potential social desirability bias, respondents were assured that all questionnaires would remain anonymous (Podsakoff et al., 2003; Spector, 2006). Studies 2 and 4 incorporated additional design features to limit the possibility of social desirability bias. Not only were respondents assured anonymity, but coworkers provided measures of the dependent variables (i.e., organization- and supervisor-directed deviance), which, given their undesirable nature, may be most susceptible to such bias. Furthermore, we included focal employee social desirability as a control variable in Study 4 (Podsakoff et al., 2003; Spector, 2006). Finally, we included a lab experiment in Study 5 that addresses this concern.

Another potential limitation is that all four field studies may suffer from common-method bias, because we assessed all variables via survey data (Podsakoff et al., 2003). However, self-report data are justified given the nature of the variables being investigated (Ellsworth, 1995; Spector, 1994). As the focus of the studies is on the effects of perceived, rather than actual, mistreatment, only self-report data could be used. Self-report data are also most appropriate for both competence uncertainty and hostility because, as internal states, they may be most accurately reported by the individual experiencing them. In addition, the lab experiment helps address common-method variance concerns.

Three of the four survey studies were also each administered at one point in time, and therefore, do not allow any inferences to be made regarding causality. It is possible that employees first engage in deviant behavior and subsequently, 
are mistreated by their supervisors. Study 5 rules out this possibility, and existing research further supports the causal relationships our theoretical model specifies. Research on uncertainty management theory has been dominated by experimental studies. This work, along with that which has experimentally manipulated and investigated thwarted needs, has demonstrated causal relationships between similar variables of interest. Therefore, it is reasonable to assume that the mediated relationship between the interaction of mistreatment and uncertainty and deviance follows the causal sequence suggested in the field studies.

In addition, although the snowball sampling method to obtain coworker ratings used in Study 2 and Study 4 has been utilized in past research (see Grant \& Mayer, 2009; Mayer et al., 2009; Skarlicki \& Folger, 1997 for examples), one may wonder whether the coworker data were provided by coworkers as opposed the focal employee. We took a number of steps to deal with this possibility. First, in introducing these studies, we emphasized the importance to the integrity of the scientific process that coworkers filled out the coworker survey. Second, we collected the data online and thus, when responses were submitted, they were time stamped and an IP address was provided. We checked the time the focal employee and coworker surveys were submitted as well as the IP addresses of the computers to make sure surveys were not submitted at almost the same time and/or IP addresses were identical and found no irregularities. However, future research should use additional methodologies to address such concerns.

\section{Conclusions}

The present studies show that although leader mistreatment motivates employees to reciprocate with deviance, leader mistreatment is a particularly strong motivator for those employees who are uncertain of their competence on the job. These results are consistent with a self-uncertainty based extension of the traditional SET-based explanation. Furthermore, and consistent with a thwarted needs based extension of SET, one psychological mechanism through which leader mistreatment and self-uncertainty interact to relate to deviance is the higher levels of hostility victimized employees experience. We hope this research will encourage continued exploration of when and why employees reciprocate leader mistreatment.

\section{Acknowledgements}

We would like to thank Maureen Ambrose, Gillan Ku, and Madan Pillutla for helpful comments on prior versions of this paper. We would also like to thank Mary Bardes and Rebecca Greenbaum for their assistance with data collection. 


\section{References}

Aiken, L. S., \& West, S. G. (1991). Multiple regression: Testing and interpreting interactions. New York: Sage.

Aquino, K., \& Douglas, S. (2003). Identity threat and antisocial behavior in organizations: The moderating effects of individual differences, aggressive modeling, and hierarchical status. Organizational Behavior and Human Decision Processes, 90, 195-208.

Aquino, K., Lewis, M. U., \& Bradfield, M. (1999). Justice constructs, negative affectivity, and employee deviance: A proposed model and empirical test. Journal of Organizational Behavior, 20,1073-1091.

Aquino, K., \& Thau, S. (2009). Workplace victimization: Aggression from the target's perspective. Annual Review of Psychology, 60, 717-741.

Ashforth, B. E. (1994). Petty tyranny in organizations. Human Relations, 47,755-778.

Axelrod, R. (1984). The evolution of cooperation. New York: Basic Books.

Bandura, A. (1997). Self-efficacy: The exercise of control. New York: W.H. Freeman.

Barclay, L. J., Skarlicki, D. P., \& Pugh, S. D. (2005). Exploring the role of emotions in injustice perceptions and retaliation. Journal of Applied Psychology, 90,629-643.

Barsky, A., \& Kaplan, S. A. (2007). If you feel bad, it's unfair: A quantitative synthesis of affect and organizational justice perceptions. Journal ofApplied Psychology, 92, 286-295.

Baumeister, R. F., \& Boden, J. M. (1998). Aggression and the self: High self-esteem, low self-control, and ego threat. In R. G. Geen \& E. D. Donnerstein (Eds.), Human aggression: Theories, research, and implications for social policy (pp. 11137). San Diego, CA: Academic Press.

Baumeister, R. F., Campbell, J. D., Krueger, J. I., \& Vohs, K. D. (2003). Does high selfesteem cause better performance, interpersonal success, happiness, or healthier lifestyles? Psychological Science in the Public Interest, 4,1-44.

Becker, L. C. (1986). Reciprocity. London and New York: Routledge.

Becker, J., Schwartz, C., Saris-Baglama, R. N., Kosinski, M., \& Bjorner, J. B. (2007). Using item response theory (IRT) for developing and evaluating the pain impact questionnaire (PIQ-6TM). Pain Medicine, 8, 129-144.

Bennett, R. J., \& Robinson, S. L. (1997). Workplace deviance: Its definition, its manifestations and its causes. In R. Lewicki, R. Bies, \& B. Sheppard (Eds.). Research on Negotiation in Organizations (Vol. 6, pp. 3-27). Stanford, CT: JAI Press.

Bennett, R. J., \& Robinson, S. L. (2000). Development of a measure of workplace deviance. Journal of Applied Psychology, $85,349-360$.

Berry, C. M., Ones, D. S., \& Sackett, P. R. (2007). Interpersonal deviance, organizational deviance, and their common correlates: A review and metaanalysis. Journal of Applied Psychology, 92, 410-424.

Bierens, H. J. (2005). Introduction to the mathematical and statistical foundations of econometrics. Cambridge, NY: Cambridge University Press.

Bies, R. J. (2001). Interactional (in)justice: The sacred and the profane. In J. Greenberg \& R. Cropanzano (Eds.), Advances in organizational behavior (pp. 89-118). San Francisco: New Lexington Press.

Blau, P. M. (1964). Exchange and power in social life. New York: Wiley.

Bradfield, M., \& Aquino, K. (1999). The effects of blame attributions and offender likableness on forgiveness and revenge in the workplace. Journal of Management, 25, 607-631.

Brockner, J., Heuer, L., Siegel, P. A., Wiesenfeld, B., Martin, C., Grover, S., et al. (1998). The moderating effect of selfesteem in reaction to voice: Converging evidence from five studies. Journal of Personality and Social Psychology, 75, 394-407.

Clark, M. S., \& Mills, J. (1979). Interpersonal-attraction in exchange and communal relationships. Journal of Personality and Social Psychology, 37,12-24. 
Cohen-Charash, Y., \& Spector, P. E. (2001). The role of justice in organizations: A meta-analysis. Organizational Behavior and Human Decision Processes, 86, 278-321.

Colquitt, J. A. (2001). On the dimensionality of organizational justice: A construct validation of a measure. Journal of Applied Psychology, 86, 386-400.

Colquitt, J. A., Conlon, D. E., Wesson, M. J., Porter, C., \& Ng, K. Y. (2001). Justice at the millennium: A meta-analytic review of 25 years of organizational justice research. Journal of Applied Psychology, 86, 425-445.

Colquitt, J. A., Scott, B. A., Judge, T. A., \& Shaw, J. C. (2006). Justice and personality: Using integrative theories to derive moderators of justice effects. Organizational Behavior and Human Decision Processes, 100,110-127.

Cropanzano, R., \& Mitchell, M. S. (2005). Social exchange theory: An interdisciplinary review. Journal of Management, 31, $874-900$.

De Cremer, D., Brebels, L., \& Sedikides, C. (2008). Being uncertain about what? Procedural fairness effects as a function of general uncertainty and belongingness uncertainty. Journal of Experimental Social Psychology, 44, 1520-1525.

De Cremer, D., \& Sedikides, C. (2005). Self-uncertainty and responsiveness to procedural justice. Journal of Experimental Social Psychology, 41, 157-173.

De Cremer, D., \& Tyler, T. R. (2005). Managing group behavior: The interplay between procedural justice, sense of self, and cooperation. Advances in Experimental Social Psychology, 37,151-218.

De Cremer, D., \& Van Hiel, A. (2008). Procedural justice effects on self-esteem under certainty versus uncertainty emotions. Motivation and Emotion, 32, 278-287.

Deci, E. L., \& Ryan, R. M. (1985). Intrinsic motivation and self-determination in human behavior. New York: Plenum Press.

Duffy, M. K., Ganster, D. C., \& Pagon, M. (2002). Social undermining in the workplace. Academy of Management Journal, 45, 331-351.

Elliot, A. J., \& Dweck, C. S. (2005). Competence and motivation. In A. J. Elliot \& C. S. Dweck (Eds.), Handbook of competence and motivation (pp. 3-12). New York, NY: Guilford.

Ellsworth, P. C. (1995). The right way to study emotion. Psychological Inquiry, 6, 213-216.

Ferris, D. L., Brown, D. J., Lian, H., \& Keeping, L. (2009). Self-esteem level and contingencies of self-worth. Journal of Applied Psychology, 94, 1345-1353.

Fiske, S. T. (2004). Developing a program of research. In C. Sansone, C. Morf, \& A. Panter (Eds.), Handbook of methods in social psychology (pp. 71-90). Thousand Oaks, CA: Sage.

Fiske, S. T., \& Taylor, S. E. (2008). Social cognition: From brains to culture. Boston: McGraw Hill.

Gouldner, A. (1960). The norm of reciprocity. American Sociological Review, 25, 161-178.

Grant, A. M., \& Mayer, D. M. (2009). Good soldiers and good actors: Prosocial and impression management motives as interactive predictors of citizenship behavior. Journal of Applied Psychology, 94, 887-899.

Greenberg, J. (1990). Employee theft as a reaction to underpayment in-equity: The hidden cost of pay cuts. Journal of Applied Psychology, 75, 561-568.

Greenberg, J. (1993). Stealing in the name of justice - Informational and interpersonal moderators of theft reactions to underpayment inequity. Organizational Behavior and Human Decision Processes, 54, 81-103.

Greenberg, J., \& Scott, K. S. (1996). Why do workers bite the hands that feed them? Employee theft as a social exchange process. In L. L. Cummings \& B. M. Staw (Eds.). Research in organizational behavior (Vol. 18, pp. 111-156). Greenwich, CT: JAI Press.

Guido, G. (2001). The salience of marketing stimuli: An incongruity-salience hypothesis on consumer awareness. Norwell, MA: Kluwer Academic Publishers.

Harter, S. (1990). Causes, correlates, and the functional role of global self-worth: A life-span perspective. In R. J. Sternberg \& J. Kolligan, Jr. (Eds.), Competence considered (pp. 67-97). New Heaven, CT: Yale University Press. 
Hoel, H., \& Cooper, C. L. (2001). Origins of bullying: Theoretical frameworks for explaining workplace bullying. In N. Tehrani (Ed.), Building a culture of respect: Managing bullying at work (pp. 3-19). London: Taylor \& Francis.

Homans, G. C. (1961). Social behavior. New York: Harcourt, Brace, \& World.

Judge, T. A., Bono, J. E., \& Locke, E. A. (2000). Personality and job satisfaction: The mediating role of job characteristics. Journal of Applied Psychology, 85, 237-249.

Judge, T. A., Locke, E. A., Durham, C. C., \& Kluger, A. N. (1998). Dispositional effects on job and life satisfaction: The role of core evaluations. Journal of Applied Psychology, 83, 17-34.

Judge, T. A., Scott, B. A., \& Ilies, R. (2006). Hostility, job attitudes, and workplace deviance: Test of a multilevel model. Journal of Applied Psychology, 91,126-138.

Kernis, M. H. (2005). Measuring self-esteem in context: The importance of stability of self-esteem in psychological functioning. Journal of Personality, 73, 1569-1605.

Lawler, E. J. (2001). An affect theory of social exchange. The American Journal of Sociology, 107, 321-352.

Lawler, E. J., \& Thye, S. R. (1999). Bringing emotions into social exchange theory. Annual Review of Sociology, 25, 217-244.

Lazarus, R. S. (1991). Emotion and adaptation. New York: Oxford University Press.

Lee, K., \& Allen, N. J. (2002). Organizational citizenship behavior and workplace deviance: The role of affect and cognitions. Journal of Applied Psychology, 87, 131-142.

Lind, E. A., \& Van den Bos, K. (2002). When fairness works: Toward a general theory of uncertainty management. Research in organizational behavior, 24, 181-223.

Mayer, D. M., Kuenzi, M., Greenbaum, R., Bardes, M., \& Salvador, R. (2009). How low does ethical leadership flow? Test of a trickle-down model. Organizational Behavior and Human Decision Processes, 108,1-13.

Mitchell, M. S., \& Ambrose, M. L. (2007). Abusive supervision and workplace deviance and the moderating effects of negative reciprocity beliefs. Journal of Applied Psychology, 92, 1159-1168.

Pelled, L. H., \& Xin, K. R. (1999). Down and out: An investigation of the relationship between mood and employee withdrawal behavior. Journal of Management, 25, 875-895.

Podsakoff, P. M., Mackenzie, S. B., Lee, J. Y., \& Podsakoff, N. P. (2003). Common method biases in behavioral research: A critical review of the literature and recommended remedies. Journal of Applied Psychology, 88, 879-903.

Preacher, K. J., Rucker, D. D., \& Hayes, A. F. (2007). Assessing moderated mediation hypotheses: Theory, methods, and prescriptions. Multivariate Behavioral Research, 42, 185-227.

Robins, R. W., Hendin, H. M., \& Trzesniewski, K. H. (2001). Measuring global selfesteem: Construct validation of a singleitem measure and the Rosenberg Self Esteem Scale. Personality and Social Psychology Bulletin, 27,151-161.

Robinson, S. L., \& Bennett, R. J. (1997). Workplace deviance: Its definition, its manifestations, and its causes. In R. J. Lewicki, B. H. Sheppard, \& R. J. Bies (Eds.). Research on negotiation in organizations (Vol. 7, pp. 3-27). Greenwich, CT: JAI Press.

Robinson, S. L., \& O'Leary-Kelly, A. M. (1998). Monkey see, monkey do: The influence of work groups on the antisocial behavior of employees. Academy of Management Journal, 41, 658-672.

Sedikides, C., De Cremer, D., Hart, C. M., \& Brebels, L. (2010). Procedural fairness responses in the context of selfuncertainty. In R. M. Arkin, K. C. Oleson, \& P. J. Carroll (Eds.), The uncertain self: A handbook of perspectives from social and personality psychology (pp. 142-159). New York, NY: Psychology Press.

Sedikides, C., \& Strube, M. J. (1995). The multiply motivated self. Personality and Social Psychology Bulletin, 12, 13301335.

Skarlicki, D. P., \& Folger, R. (1997). Retaliation in the workplace: The roles of distributive, procedural, and interactional justice. Journal of Applied Psychology, 82, 434-443.

Smith, C. A., Haynes, K. N., Lazarus, R. S., \& Pope, L. K. (1993). In search of the "hot" cognitions: Attributions, appraisals, and their relation to emotion. Journal of Personality and Social Psychology, 65, 916-929. 
Spector, P. E. (1994). Using self-report questionnaires is OB research - A comment on the use of a controversial method. Journal of Organizational Behavior, 15, 385-392.

Spector, P. E. (2006). Method variance in organizational research. Organizational Research Methods, 9, $221-232$.

Spreitzer, G. M. (1995). Psychological empowerment in the workplace: Dimensions, measurement, and validation. Academy of Management Journal, 38,1442-1465.

Strahan, R., \& Gerbasi, K. C. (1972). Short, homogenous versions of the Marlowe- Crowne social desirability scale. Journal of Clinical Psychology, 28,191-193.

Tepper, B. J. (2000). Consequences of abusive supervision. Academy of Management Journal, 43, 178-190.

Tepper, B. J., Carr, J., Breaux, D. M., Geider, S., Hu, C., \& Hua, W. (2009). Abusive supervision, intentions to quit, and employees' workplace deviance. Organizational Behavior and Human Decision Processes, 109,156-167.

Tepper, B. J., Duffy, M. K., Henle, C. A., \& Lambert, L. S. (2006). Procedural injustice, victim precipitation, and abusive supervision. Personnel Psychology, 59, 101-123.

Thau, S., Aquino, K., \& Poortvliet, P. M. (2007). Self-defeating behaviors in organizations: The relationship between thwarted belonging and interpersonal work behaviors. Journal of Applied Psychology, 92, 840-847.

Thau, S., Aquino, K., \& Wittek, R. (2007). An extension of uncertainty management theory to the self: The relationship between justice, social comparison orientation, and antisocial work behaviors. Journal of Applied Psychology, 92, 250258.

Thau, S., Bennett, R. J., Mitchell, M. S., \& Marrs, M. B. (2009). How management style moderates the relationship between abusive supervision and workplace deviance: An uncertainty management theory perspective. Organizational Behavior and Human Decision Processes, 108, 79-92.

Tice, D. M., Baumeister, R. F., \& Zhang, L. (2004). The role of emotion in self regulation: Differing role of positive and negative emotions. In P. Philippot \& R.

S. Feldman (Eds.), The regulation of emotion (pp. 213-226). Mahwah, NJ: Erlbaum.

Tobin, J. (1958). Estimation of relationships for limited dependent variables. Econometrica, 26, 24-36.

Tyler, T. R. (1999). Why people cooperate with organizations: An identity-based perspective. In B. Staw \& R. Sutton (Eds.). Research in organizational behavior (Vol. 21, pp. 201-246). Greenwich, CT: JAI Press.

Tyler, T. R., \& Lind, E. A. (1992). A relational model of authority in groups. In M. Zanna (Ed.). Advances in experimental social psychology (Vol. 25, pp. 115-191). New York: Academic Press.

Van den Bos, K. (2001). Uncertainty management: The influence of uncertainty salience on reactions to perceived procedural fairness. Journal of Personality and Social Psychology, 80, 931-941.

Van den Bos, K., \& Lind, E. A. (2002). Uncertainty management by means of fairness judgments. In M. P. Zanna (Ed.). Advances in experimental social psychology (Vol. 34, pp. 1-60). San Diego, CA: Academic Press.

Van Prooijen, J. W., Van den Bos \& Wilke, H. A. M. (2002). Procedural justice and status: Status salience as antecedent of procedural fairness effects. Journal of Personality and Social Psychology, 83, 1353-1361.

Watson, D., \& Clark, L. A. (1994). The PANAS-X: Manual for the positive and negative affect schedule - expanded form. Unpublished, University of lowa.

White, R. W. (1959). Motivation reconsidered: The concept of competence. Psychological Review, 66, 297-333.

Wiesenfeld, B., Swann, W., Jr., Brockner, J., \& Bartel, C. (2007). Is more fairness always preferred? Self-esteem moderates reactions to procedural justice. Academy of Management Journal, 50, 1235-1253.

Zoomerang (2005). Panel health: The real competitive advantage. San Francisco: Market Tools. 